\title{
Physical Activity, Body Mass Index, and Clustered Metabolic Risk in U.S. Adolescents: 2007-2012 NHANES.
}

\author{
Bethany Dawn Williams \\ University of North Florida, n00771498@unf.edu
}

Follow this and additional works at: https://digitalcommons.unf.edu/etd

Part of the Epidemiology Commons, and the Exercise Science Commons

\section{Suggested Citation}

Williams, Bethany Dawn, "Physical Activity, Body Mass Index, and Clustered Metabolic Risk in U.S. Adolescents: 2007-2012 NHANES." (2017). UNF Graduate Theses and Dissertations. 745.

https://digitalcommons.unf.edu/etd/745

This Master's Thesis is brought to you for free and open access by the Student Scholarship at UNF Digital Commons. It has been accepted for inclusion in UNF Graduate Theses and Dissertations by an authorized administrator of UNF Digital Commons. For more information, please contact Digital Projects.

(C) 2017 All Rights Reserved

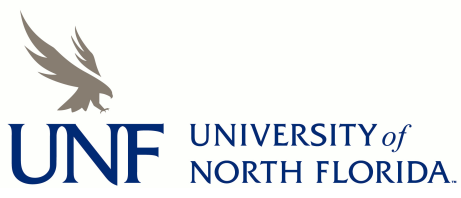


PHYSICAL ACTIVITY, BODY MASS INDEX AND CLUSTERED METABOLIC RISK IN U.S. ADOLESCENTS: 2007-2012 NHANES.

by

Bethany Dawn Williams

A thesis submitted to the Department of Clinical \& Applied Movement Sciences in partial fulfillment of the requirements for the degree of Master of Science in Exercise

Science and Chronic Disease

UNIVERSITY OF NORTH FLORIDA

BROOKS COLLEGE OF HEALTH

April, 2017 
The thesis of Bethany D. Williams is approved:

(Date)

Dr. James R. Churilla, Ph.D., M.P.H., M.S., RCEP, FACSM

Committee Chairperson

Dr. Tammie M. Johnson, Dr.P.H., M.P.H.

Committee Member

Dr. Susan B. Sisson, Ph.D., RDN, CHES, FACSM

Committee Member

Dr. Chris A. Ardern, Ph.D.

Committee Member

Dr. Katrina D. DuBose, Ph.D., FACSM

Committee Member

M. Ryan Richardson, M.S.H., ACSM EP-C

Research Consultant

Accepted for the Department:

Dr. Joel W. Beam, Ed.D, ATC, LAT

Chair, Department of Clinical \& Applied Movement Sciences

Accepted for the College:

Catherine Christie, Ph.D., RD, LD/N, FADA

Associate Dean, Brooks College of Health

Accepted for the University:

Dr. John Kantner, Ph.D., M.A.

Dean of the Graduate School 


\section{Dedication \& Acknowledgements}

Few scholars find themselves having accomplished a great deal without help. In my case, I am very fortunate to have had such a strong, unyielding system of support as I worked towards completing my Master's program. I would like to dedicate my thesis project to my family. Thank you for your advice, encouragement, and constant inspiration.

I would also like to thank Scott Kientz, who stood by my side as my partner and best friend as I worked towards achieving a Master's degree as well as completing this project. Thank you for your unconditional patience, love, sacrifice, and for always having faith in me.

I would like to thank the faculty of the UNF Clinical and Applied Movement Sciences Department, and my all-star thesis committee, including Dr. Tammie M. Johnson, Dr. Chris A. Ardern, Dr. Susan B. Sisson, and Dr. Katrina D. DuBose. I so greatly appreciate each of you for your contributions towards my thesis project, and for your mentorship. I would like to also acknowledge my two fellow graduate research assistants, Brandi Rariden and Adrian Boltz. Thank you for sharing in my final year as a thesis student. I wish you both the best in your future endeavors.

A very special thanks also goes to Mr. Ryan Richardson, who served as a research consultant on my thesis project while also being an exemplary role model and friend. Last but not least, I would like to thank my mentor and committee chairperson, Dr. James Churilla for expecting nothing less than excellence from the beginning. My future successes will be owed to the example you have set for me as a researcher, professor, mentor, and as a person. 


\section{Table of Contents}

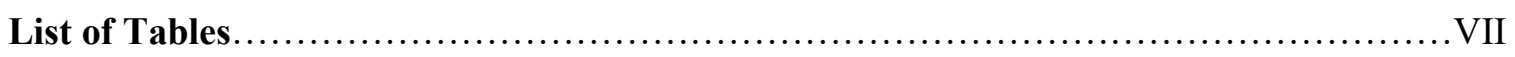

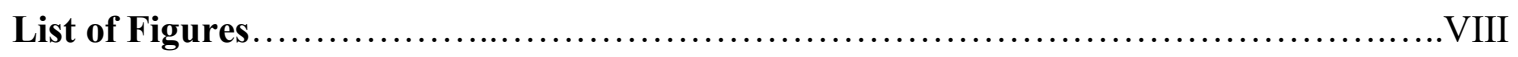

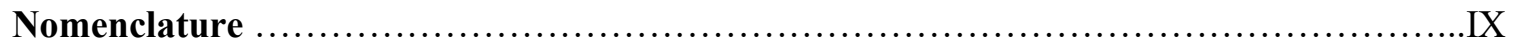

List of Abbreviations..............................................................

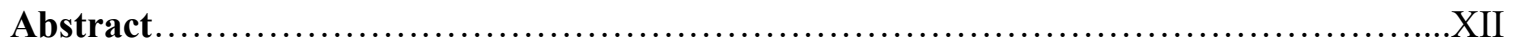

Chapter One: Introduction.....................................................

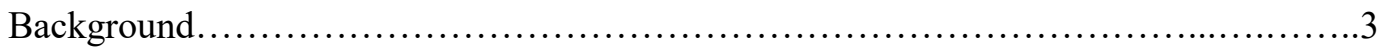

PA and Metabolic Risk ................................................

BMI and Metabolic Risk ..............................................

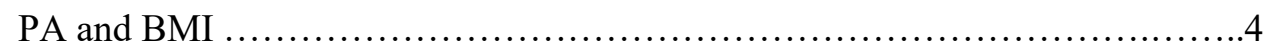

PA Recommendations for U.S. Adolescents ...............................5

BMI \& Prevalence of Overweight/Obese Adolescents ...........................5

Estimated Prevalence of Individual Metabolic Risk Factors in U.S. Adolescents ........6

Abbreviated Literature Review ..............................................

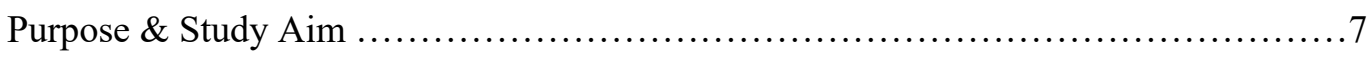

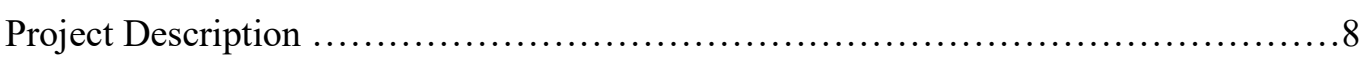

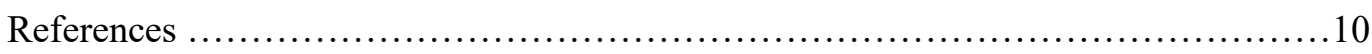

Chapter Two: Review of Literature ..................................................18

Metabolic Risk ...........................................................19

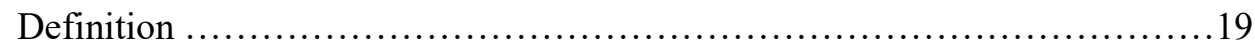

Estimated Prevalence in Adolescents ................................. 20

The Independent Relationship between PA and Metabolic Risk .................................20

Clustered Metabolic Risk Score .......................................20

Individual Metabolic Components .....................................26 
The Role of Adiposity in Mediating the Relationship between PA and Metabolic Risk.29

Clustered Metabolic Risk Score .........................................29

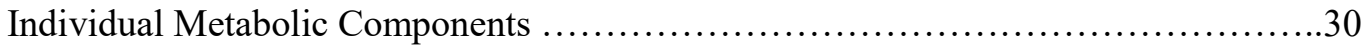

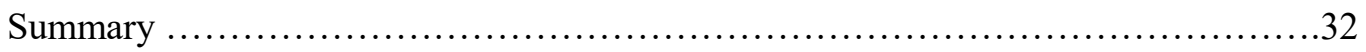

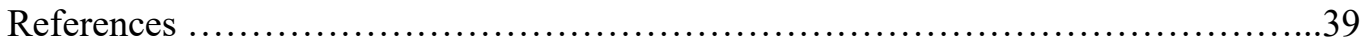

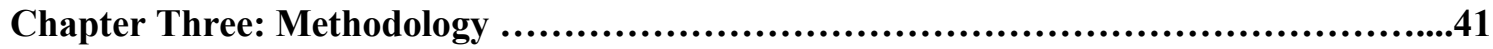

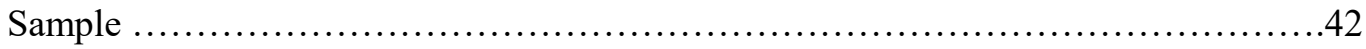

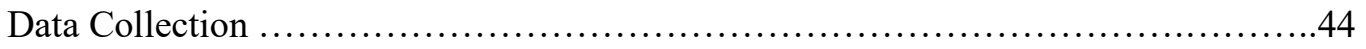

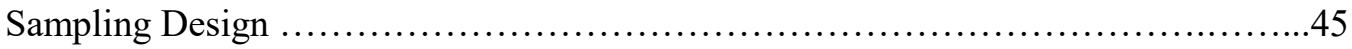

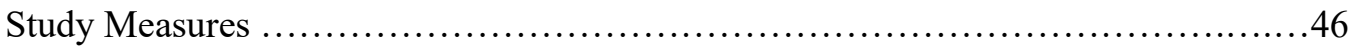

Dependent measure(s): Clustered metabolic risk score .....................46

Primary independent measure(s): Physical activity and body mass index ......47

Other Independent Measures ............................................49

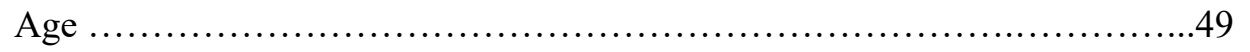

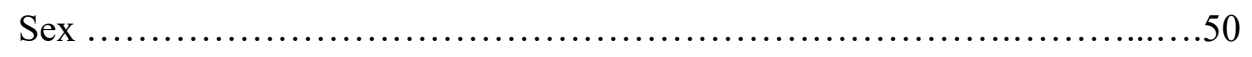

Race/Ethnicity ...................................................50

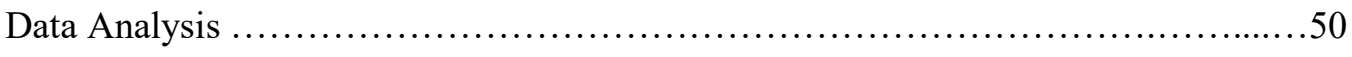

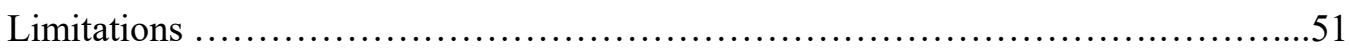

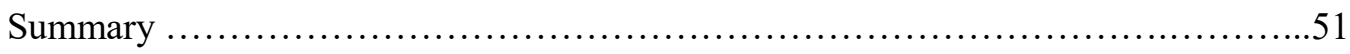

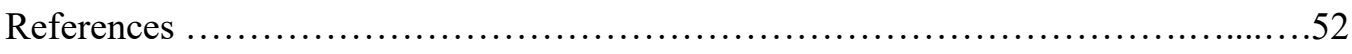

Chapter Four: Physical Activity, Body Mass Index and Clustered Metabolic Risk in U.S.

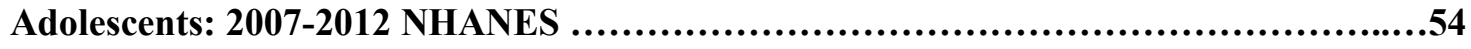

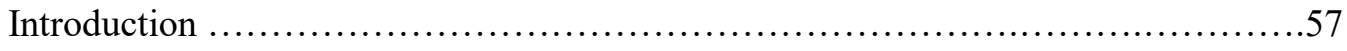

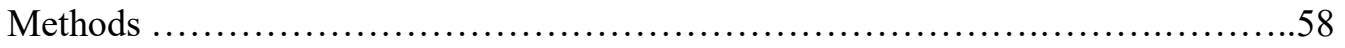

Physical Activity ...............................................58

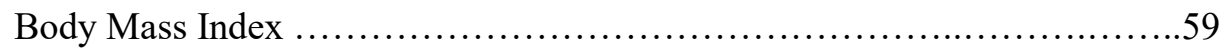


Clustered Metabolic Risk .60

Statistical Analysis .60

Results 61

Discussion .66

References

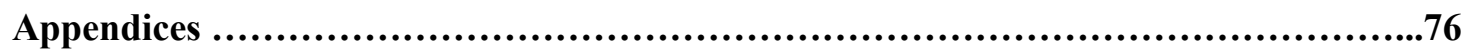

Appendix A: University of North Florida IRB Approval Letter ....................77

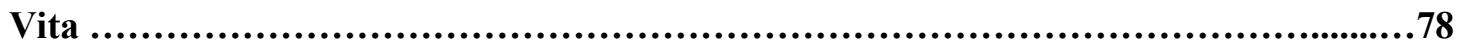




\section{List of Tables}

Table

Page

\section{Chapter Two: Review of Literature}

1. Summary of studies examining the associations between BMI, PA and cMetS score in children/adolescents

Chapter Four: Physical Activity, Body Mass Index and Clustered Metabolic Risk in U.S. Adolescents: 2007-2012 NHANES

1. Sample Demographic Characteristics of U.S. Adolescents Aged 12-17

(Weighted), Stratified by Sex $(n=875)$

2. Association between BMI/PA categorization and cMetS score (MAP, FG, HDLC, TRI) in U.S. adolescents: 2007-2012 NHANES .63

3. Association between BMI/PA categorization and cMetS score components (MAP, FG, HDL-C, TRI) in U.S. adolescent males: NHANES 2007-2012 ...........65

4. Association between BMI/PA categorization and cMetS score components (MAP, FG, HDL-C, TRI) in U.S. adolescent females: NHANES 2007-2012 .........65 


\section{List of Figures}

Table

Page

\section{Chapter Three: Methodology}

1. Flow chart of sample inclusion

Chapter Four: Physical Activity, Body Mass Index and Clustered Metabolic Risk in U.S.

Adolescents: 2007-2012 NHANES

1. Association between BMI/PA categorization and cMetS score in U.S. adolescents gender-stratified: NHANES 2007-2012 . 
Nomenclature

$$
\text { cpm }
$$

h/day

$\mathrm{h} / \mathrm{wk}$

$\mathrm{kcal} / \mathrm{kg} / 15 \mathrm{~min}$

$\mathrm{kg}$

$\mathrm{m}$

$\mathrm{mg} / \mathrm{dL}$

$\min /$ day counts per minute

hours per day

hours per week

kilocalories per kilogram per fifteen minutes

kilograms

meters

milligrams per deciliter

minutes per day 


\section{List of Abbreviations}

BMI

BP

CAPI

CASPIAN

CHD

CI

cMetS

CVD

DU

DXA

FPG

GPAQ

HDL-C

HOMA-IR

LTPA

MAP

MEC

MET body mass index

blood pressure

computer-assisted personal interviewing

Childhood and Adolescence Surveillance and

Prevention of Adult Non-Communicable Disease

coronary heart disease

confidence interval

clustered metabolic risk

cardiovascular disease

dwelling unit

dual-energy x-ray absorptiometry

Fasting plasma glucose

Global Physical Activity Questionnaire

high-density lipoprotein cholesterol

homeostasis model assessment-estimated insulin

resistance

leisure-time physical activity

mean arterial pressure

mobile examination center

metabolic equivalent 
MetS

MVPA

NCEP ATP III

NHANES

NOA

NONA

OA

ONA

OR

PA

PANIC

PSU

SAS

SB

SE

TC

TG

TPAV

WC

WHO

$\mathrm{VO}_{2} \max$ metabolic syndrome

moderate-to-vigorous physical activity

National Cholesterol Education Program Expert Panel

on Detection, Evaluation and Treatment of High

Blood Cholesterol in Adults

National Health and Nutrition Examination Survey

not overweight/active

not overweight/not active

overweight/active

overweight/not active

odds ratio

physical activity

Physical Activity and Nutrition in Children

primary sampling unit

Statistical Analysis Software

sedentary behavior

standard error

total cholesterol

triglycerides

total physical activity volume

waist circumference

World Health Organization

maximal oxygen consumption 


\begin{abstract}
Objectives To examine variation in clustered metabolic risk (cMetS) in adolescents classified as not overweight/active (NOA), not overweight/not active (NONA), overweight/active (OA), and overweight/not active (ONA).
\end{abstract}

Background While studies to date have shown that children and adolescents who meet the current physical activity (PA) recommendations and maintain a healthy body weight demonstrate significantly lower cardiometabolic risk, there are some studies that suggest the relationship between PA and metabolic risk may be mediated by adiposity.

Methods The sample included adolescent participants $(\mathrm{n}=875 ; 12-17$ years $)$ of the 2007-2012 National Health and Nutrition Examination Survey (NHANES). The cMetS score included triglycerides, high-density lipoprotein cholesterol, fasting plasma glucose, and mean arterial pressure. Age- and sex-specific body mass index (BMI) percentiles were utilized; overweight was defined as BMI percentile $\geq 85^{\text {th }}$. Activity data included self-reported frequency of moderate-to-vigorous PA. Adolescents reporting $\geq 60 \mathrm{~min} /$ day of PA were considered "active". General linear models, adjusted for age, sex, and raceethnicity, were used. A six-year fasting sample weight was applied to the analyses in order to ensure representativeness of the data. 
Results The cMetS scores were significantly $(\mathrm{p}<0.05)$ higher in OA and ONA adolescents when compared to NOA ( $\beta=1.08$ and $\beta=1.57$, respectively). In ONA males, cMetS was significantly $(\mathrm{p}<0.01)$ higher when compared to NOA males. In OA and ONA females, cMetS scores were significantly higher compared to the referent group ( $\mathrm{p}<0.01$ for both).

Conclusions The cMetS scores were higher in OA and ONA adolescents when compared to those classified as NOA. Whereas only ONA males demonstrated significantly higher cMetS score when compared to the NOA referent, both OA and ONA cMetS scores (vs NOA) were significantly higher in females. 
Chapter One: Introduction 
Daily, routine physical activity (PA) among children and youth is known to improve cardiovascular and metabolic disease risk profiles (1-3) and reduce the risk for a plethora of undesirable health-related outcomes in adulthood $(1,4)$. Adiposity is also a strong predictor for multiple comorbidities in adolescents (5-7). Current data strongly suggest that excess adiposity in youth is significantly associated with unfavorable outcomes in adulthood, including obesity, increased risk of developing cardiovascular disease (CVD) and premature mortality (8-12). Metabolic syndrome (MetS) is an unhealthy cluster of CVD risk factors which include abnormal blood pressure (BP), elevated triglycerides (TG), low high-density lipoprotein cholesterol (HDL-C), elevated fasting plasma glucose (FPG) and abnormal waist circumference (WC). Research indicates that MetS prevalence has increased in U.S. adolescents (13-15). While Cook et al. (14) estimated the MetS prevalence to be $4.1 \%$ in a sample of U.S. adolescents from 1999-2002, Miller et al. (15) observed a prevalence of $10.1 \%$ in a sample collected between the years 2001-2010. Clustered metabolic risk is often represented by a continuous z-score, which typically takes into account components of MetS; the score may also include other cardiometabolic risk factors such as hyperinsulinemia or a homeostasis model assessment - estimated insulin resistance (HOMA-IR). This chapter provides an overview of the previous research exploring relationships between PA, body mass index (BMI) and metabolic risk in adolescents. Background information, including the current PA recommendations, the definition of "healthy weight" and "overweight" based on BMI, and the prevalence of metabolic risk in U.S. adolescents will also be discussed. The chapter will conclude by clarifying the problem and the purpose of the research question, and will provide a brief description of the project. 


\section{Background}

\section{PA and Metabolic Risk}

Physical activity and healthy body weight have both been shown to be independently correlated with a lower likelihood of metabolic risk in all age groups $(5,16-25)$. According to the 2008 Physical Activity Guidelines for Americans (16), meeting the federal PA guidelines is inversely related to premature death, coronary heart disease (CHD), stroke, cancer, type 2 diabetes, abnormal blood pressure, high total cholesterol, and sudden heart attack. Specifically in children and adolescents, those who are physically active have higher levels of cardiorespiratory fitness, stronger muscles, lower body fatness, stronger bones and reduced symptoms of anxiety and depression when compared to those who are inactive. Youth who engage in regular PA according to the federal PA guidelines also demonstrate a greater likelihood of being healthy adults, due to their lower likelihood of cardiometabolic risk factor development during childhood and adolescence (16).

It has been suggested in the literature that the relationship between PA and metabolic risk is no longer statistically significant following adjustment for varying measures of adiposity (16-19). However, many studies have observed that PA, independent of adiposity, is significantly and inversely related to clustered metabolic risk in children and adolescents $(5,20-25)$. 
Body mass index is a measure of adiposity based on one's weight in relation to their height [weight $(\mathrm{kg}) /$ height $\left.^{2}\left(\mathrm{~m}^{2}\right)\right]$. In an analysis involving over 4,200 children and adolescents 8-17 years of age, BMI was shown to be comparable to waist circumference and waist-to-height ratio when predicting the clustering of metabolic risk (26). The same analysis suggested that being overweight (as defined by BMI $\geq 85^{\text {th }}$ percentile for age and sex) was associated with more than two times the odds for having clustered metabolic risk, and being obese (BMI $\geq 95^{\text {th }}$ percentile) was associated with more than 14 times the odds when compared with those within the desirable weight category $\left(\mathrm{BMI}<85^{\text {th }}\right.$ percentile). In this case, clustered metabolic risk was operationalized as the sum of zscores for TG, HDL-C, systolic and diastolic BP (mean arterial pressure), and HOMA-IR. Several studies have illustrated that with an increased BMI, children and adolescents are more likely to also possess various metabolic risk factors (27-30). Along with the immediate health implications of undesirable BMI in youth, the numerous long-term health consequences that develop in adulthood further highlight the importance of maintaining a healthy lifestyle during childhood and adolescence $(8-12,31,32)$. It should be noted that BMI is essentially a proxy for obesity, which is a chronic condition heavily associated with a number of unhealthy dietary and lifestyle habits. These contributors will affect the degree of one's obesity-related health risk.

\section{$P A$ and $B M I$}

While those who are physically active are less likely to be overweight and obese, the reverse concept that those who are overweight and obese are less likely to be physically active has been established $(2,4,5,33,34-38)$; this is sometimes referred to as 
reverse epidemiology. Increased volumes of PA have been consistently shown to be inversely and significantly associated with increased body weight $(2,4,5,33,34)$. Interestingly, some studies suggest that overall PA may not differ significantly between BMI groups in children and adolescents; however, those who are normal weight exhibit significantly higher levels of strenuous PA, and are more likely to participate in sports (35-37). However, it is observed in the literature that weight status is significantly and positively associated with overall PA, as well (38).

\section{PA Recommendations for U.S. Adolescents}

The 2008 Physical Activity Guidelines for Americans recommend that children and adolescents participate in at least 60 minutes of moderate-to-vigorous physical activity (MVPA) per day; however, it is also recommended that at least three days per week should incorporate vigorous-intensity activity (39). These 60 minutes daily should include muscle and bone strengthening activities at least three days per week. The Guidelines state that MVPA can be any aerobic activities which induce sweating or increased respiration, such as running, swimming, and bicycling. Unfortunately, within samples of U.S. children and adolescents collected as recently as 2012, only about one quarter are meeting the federal daily recommendation $(34,40,41)$.

\section{BMI \& Prevalence of Overweight/Obese Adolescents}

Cutoffs for BMI are based on age- and sex-specific percentiles, which were created in order to be utilized by clinicians to identify children who are at risk for becoming overweight at older ages (42). According to an expert committee comprised of 
representatives from 15 national health care organizations, a child or adolescent with a $\mathrm{BMI} \geq 5^{\text {th }}$ percentile and $<85^{\text {th }}$ percentile is considered being of healthy weight. Being overweight is defined as having a BMI $\geq 85^{\text {th }}$ and $<95^{\text {th }}$ percentile, and being obese is associated with a BMI $\geq 95^{\text {th }}$ percentile (43). Recent prevalence estimates (2009-2010) suggest that among U.S. children and adolescents aged 2-19 years, 31.8\% were overweight or obese, $16.9 \%$ were obese, and $12.3 \%$ were at or above the $97^{\text {th }}$ percentile (severely obese) of BMI for age (44). Specifically, among those aged 2-5, 6-11, and 1219 years, prevalence of overweight was $26.7 \%, 33.2 \%$, and $32.6 \%$, respectively and the prevalence of obesity was $12.1 \%, 18.0 \%$, and $18.4 \%$, respectively. Trend analyses indicate that from 1999 to 2010, an annual increase in the odds of obesity prevalence has been observed in children and adolescents ages 2-19 years [OR 1.03 (95\% CI, 1.01-1.05) and OR 1.01 (95\% CI, 0.99-1.03) for males and females, respectively].

\section{Estimated Prevalence of Individual Metabolic Risk Factors in U.S. Adolescents}

Adolescent cut-off points for the metabolic risk factors below are based on a modified definition of adult MetS in the Third Report of the National Cholesterol Education Program Expert Panel on Detection, Evaluation and Treatment of High Blood Cholesterol in Adults (45). The individual criteria are listed as follows: systolic or diastolic BP $\geq 90$ th percentile (age, height, and sex-specific), TG $\geq 110 \mathrm{mg} / \mathrm{dL}, \mathrm{HDL}-\mathrm{C} \leq 40 \mathrm{mg} / \mathrm{dL}$, and FPG concentration $\geq 100 \mathrm{mg} / \mathrm{dL}$. In a study utilizing a nationally representative sample of U.S. adolescents (12-19) who participated in the 2000-2010 National Health and Nutrition Examination Survey (NHANES), it was reported that the overall unweighted prevalence of abnormal BP, elevated TG, low HDL-C and elevated FPG were 4.9\%, 
$20.6 \%, 16.1 \%$, and $16.5 \%$, respectively (15). Abnormal BP was most common in nonHispanic black adolescents, both elevated TG and low HDL-C were most common in non-Hispanic white adolescents, and Hispanic adolescents demonstrated the highest prevalence of elevated FPG. Also, adolescent males, when compared to females, displayed a higher prevalence of MetS as well as each individual MetS criterion (15).

\section{Abbreviated Literature Review}

Studies to date have shown that children and adolescents who meet the current PA recommendations and maintain a healthy BMI demonstrate significantly lower cardiometabolic risk (20-25). However, there are some studies that suggest the relationship between PA and metabolic risk may be mediated by BMI (47-49). To our knowledge, these two variables have yet to be examined in an analysis in which adolescents are categorized by PA and BMI. There is a need to examine potential differences in cardiometabolic risk within a nationally representative sample of U.S. adolescents categorized by both PA and BMI.

\section{Purpose \& Study Aims}

The purpose of this study was to examine the potential differences in a continuous metabolic risk score (cMetS score) between groups of adolescents who were categorized by PA level and BMI. The groups were structured as follows: not overweight/active (NOA); not overweight/not active (NONA); overweight/active (OA); and overweight/not active (ONA). Study aims included examining the associations between meeting the daily federal PA recommendation, BMI, and metabolic risk score in U.S. adolescents. The 
present study also aimed to examine potential sex differences in the relationship between PA, BMI, and cMetS score. To our knowledge, this is the first study to examine the change in continuous cMetS score among categories based on meeting the daily PA recommendation and BMI in a nationally representative sample of U.S. adolescents aged 12-17 who participated in the 2007-2012 NHANES.

\section{Project Description}

This study utilized six years of data (three cycles) from the 2007-2012 NHANES, and the nationally representative sample included adolescents $12-17$ years of age. All participants attended the morning examination session in the mobile examination center (MEC) following a minimum overnight fasting period of nine hours. Females included in the analyses were not pregnant, and the sample was limited to participants with complete data on all variables of interest.

The continuous metabolic risk score was derived by standardizing and then summing the following cardiometabolic components to create a summary z-score: TG, HDL-C, FPG, and mean arterial pressure (MAP). The purpose of using a continuously distributed variable was to effectively maximize statistical power.

Weight category was determined using BMI; a participant was considered "Not Overweight" if BMI $<85^{\text {th }}$ percentiles (age- and sex- specific), and "Overweight" if BMI $\geq 85$ th percentiles. Participation in PA was determined using self-report interview data. The mean number of minutes of MVPA per day was determined for each participant. This was calculated by first multiplying average minutes per day and average days per week of MVPA, then dividing this quantity by seven (46). Participants were considered 
"Active" if their average minutes per day was $\geq 60$, which coincides with meeting the daily aerobic federal PA recommendation for adolescents. Participants were considered "Not Active" if their average minutes per day was $<60$.

The data were initially managed in SAS 9.4 (5). Variable recoding was performed as well as data coding validation. Linear regression of the overall sample was performed SAS, using PROC SURVEYREG, to observe the continuous relationship between cMetS score (dependent variable) and categorization based on PA and BMI. The mean and standard deviation of each variable for the entire sample was calculated using SAS. Strengths of the proposed study included: the use of a nationally representative sample resulting in strong external validity; large sample size to increase statistical power; the use of mostly objective means of measurement; and a continuously distributed outcome measure which serves to maximize statistical power. Limitations included: lack of inferred causality due to the cross-sectional study design, and the use of self-reported physical activity, which introduces potential recall and report bias. 


\section{References}

1. Anderson L, Harro M, Sardinha L, Froberg K, Ekelund U, Brage S, et al. Physical activity and clustered cardiovascular risk in children: A cross-sectional study (the European Youth Heart Study). Lancet. 2006(368):299-304.

2. Boreham C, Riddoch C. The physical activity, fitness and health of children. JSports Sci. 2001(19):915-29.

3. Carson V, Ridgers ND, Howard BJ, Winkler EA, Healy GN, Owen N, et al. Light-intensity physical activity and cardiometabolic biomarkers in US adolescents. PLoS One. 2013;8(8):e71417.

4. Steinberger J, Daniels SR, American Heart Association Atherosclerosis Hp, and Obesity in the Young Committee (Council on Cardiovascular Disease in the Young), American Heart Association Diabetes Committee (Council on Nutrition PyA, and Metabolism). Obesity, insulin resistance, diabetes, and cardiovascular risk in children: an American Heart Association scientific statement from the Atherosclerosis, Hypertension, and Obesity in the Young Committee (Council on Cardiovascular Disease in the Young) and the Diabetes Committee (Council on Nutrition, Physical Activity, and Metabolism). Circulation. 2003;107(10):144853.

5. Ekelund U, Brage S, Froberg K, Harro M, Anderssen SA, Sardinha LB, et al. TV viewing and physical activity are independently associated with metabolic risk in children: the European Youth Heart Study. PLoS Med. 2006;3(12):e488. 
6. Sinha R, Fisch G, Teague B, Tamborlane WV, Banyas B, Allen K, et al. Prevalence of impaired glucose tolerance among children and adolescents with marked obesity. N Engl J Med. 2002;346(11):802-10.

7. Ball GD, McCargar LJ. Childhood obesity in Canada: a review of prevalence estimates and risk factors for cardiovascular diseases and type 2 diabetes. Can J Appl Physiol. 2003;28(1):117-40.

8. Whitaker RC, Wright JA, Pepe MS, Seidel KD, Dietz WH. Predicting obesity in young adulthood from childhood and parental obesity. $N$ Engl J Med. 1997;337(13):869-73.

9. Eisenmann JC, Wickel EE, Welk GJ, Blair SN. Relationship between adolescent fitness and fatness and cardiovascular disease risk factors in adulthood: the Aerobics Center Longitudinal Study (ACLS). Am Heart J. 2005;149(1):46-53.

10. Baker JL, Olsen LW, Sørensen TI. Childhood body-mass index and the risk of coronary heart disease in adulthood. $N$ Engl J Med. 2007;357(23):2329-37.

11. van Dam RM, Willett WC, Manson JE, Hu FB. The relationship between overweight in adolescence and premature death in women. Ann Intern Med. 2006;145(2):91-7.

12. JY, KY, J J, al. e. The Association of Adolescent Fatness and Fitness With Risk Factors for Adult Metabolic Syndrome: A 22-Year Follow-up Study. Journal of Physical Activity and Health. 2014;4(11):823-30.

13. Johnson WD, Kroon JJ, Greenway FL, Bouchard C, Ryan D, Katzmarzyk PT. Prevalence of risk factors for metabolic syndrome in adolescents: National Health 
and Nutrition Examination Survey (NHANES), 2001-2006. Arch Pediatr Adolesc Med. 2009;163(4):371-7.

14. Cook S, Auinger P, Li C, Ford ES. Metabolic syndrome rates in United States adolescents, from the National Health and Nutrition Examination Survey, 19992002. J Pediatr. 2008;152(2):165-70.

15. Miller JM, Kaylor MB, Johannsson M, Bay C, Churilla JR. Prevalence of metabolic syndrome and individual criterion in US adolescents: 2001-2010 National Health and Nutrition Examination Survey. Metab Syndr Relat Disord. 2014;12(10):527-32.

16. Bailey DP, Boddy LM, Savory LA, Denton SJ, Kerr CJ. Associations between cardiorespiratory fitness, physical activity and clustered cardiometabolic risk in children and adolescents: the HAPPY study. Eur J Pediatr. 2012;171(9):1317-23.

17. Väistö J, Eloranta AM, Viitasalo A, Tompuri T, Lintu N, Karjalainen P, et al. Physical activity and sedentary behaviour in relation to cardiometabolic risk in children: cross-sectional findings from the Physical Activity and Nutrition in Children (PANIC) Study. Int J Behav Nutr Phys Act. 2014;11:55.

18. Rendo-Urteaga T, de Moraes AC, Collese TS, Manios Y, Hagströmer M, Sjöström M, et al. The combined effect of physical activity and sedentary behaviors on a clustered cardio-metabolic risk score: The Helena study. Int J Cardiol. 2015;186:186-95.

19. Rizzo NS, Ruiz JR, Hurtig-Wennlöf A, Ortega FB, Sjöström M. Relationship of physical activity, fitness, and fatness with clustered metabolic risk in children and adolescents: the European youth heart study. J Pediatr. 2007;150(4):388-94. 
20. Ekelund U, Anderssen SA, Froberg K, Sardinha LB, Andersen LB, Brage S, et al. Independent associations of physical activity and cardiorespiratory fitness with metabolic risk factors in children: the European youth heart study. Diabetologia. 2007;50(9):1832-40.

21. Ekelund U, Luan J, Sherar LB, Esliger DW, Griew P, Cooper A, et al. Moderate to vigorous physical activity and sedentary time and cardiometabolic risk factors in children and adolescents. JAMA. 2012;307(7):704-12.

22. Hong HR, Cho JK, Lee JY, Park JK, Kang HS. Clustering of metabolic syndrome risk factors associated with lifestyle factors and serum leptin in Korean children. Pediatr Exerc Sci. 2011;23(2):270-80.

23. Pahkala K, Heinonen OJ, Lagström H, Hakala P, Hakanen M, Hernelahti M, et al. Clustered metabolic risk and leisure-time physical activity in adolescents: effect of dose? Br J Sports Med. 2012;46(2):131-7.

24. Banks L, Manlhiot C, Dobbin SW, Gibson D, Stearne K, Davies-Shaw J, et al. Physical activity interacts with adiposity in determining cardiometabolic risk in adolescents. Pediatr Exerc Sci. 2012;24(4):537-48.

25. Chaput JP, Lambert M, Mathieu ME, Tremblay MS, O' Loughlin J, Tremblay A. Physical activity vs. sedentary time: independent associations with adiposity in children. Pediatr Obes. 2012;7(3):251-8.

26. Sardinha LB, Santos DA, Silva AM, Grøntved A, Andersen LB, Ekelund U. A Comparison between BMI, Waist Circumference, and Waist-To-Height Ratio for Identifying Cardio-Metabolic Risk in Children and Adolescents. PLoS One. 2016;11(2):e0149351. 
27. Freedman DS, Dietz WH, Srinivasan SR, Berenson GS. The relation of overweight to cardiovascular risk factors among children and adolescents: the Bogalusa Heart Study. Pediatrics. 1999;103(6 Pt 1):1175-82.

28. Freedman DS, Mei Z, Srinivasan SR, Berenson GS, Dietz WH. Cardiovascular risk factors and excess adiposity among overweight children and adolescents: the Bogalusa Heart Study. J Pediatr. 2007;150(1):12-7.e2.

29. Cook S, Weitzman M, Auinger P, Nguyen M, Dietz WH. Prevalence of a metabolic syndrome phenotype in adolescents: findings from the third National Health and Nutrition Examination Survey, 1988-1994. Arch Pediatr Adolesc Med. 2003;157(8):821-7.

30. Katzmarzyk PT, Srinivasan SR, Chen W, Malina RM, Bouchard C, Berenson GS. Body mass index, waist circumference, and clustering of cardiovascular disease risk factors in a biracial sample of children and adolescents. Pediatrics. 2004;114(2):e198-205.

31. Li X, Li S, Ulusoy E, Chen W, Srinivasan SR, Berenson GS. Childhood adiposity as a predictor of cardiac mass in adulthood: the Bogalusa Heart Study. Circulation. 2004;110(22):3488-92.

32. dos Santos FK, Gomes TNQF, de Souza MC, Chaves RN, e Santos DMdV, Pereira SIS, et al. Physical Activity, BMI and metabolic risk in Portuguese adolescents. Rev Bras Cineantropom Desempenho Hum. 2016;18(1):103-13.

33. 2008 Physical Activity Guidelines for Americans: Be Active, Healthy, And Happy! : U.S. Department of Health and Human Services; 2008. p. 7-20. 
34. Dentro KN, Beals K, Crouter SE, Eisenmann JC, McKenzie TL, Pate RR, et al. Results from the United States' 2014 report card on physical activity for children and youth. J Phys Act Health. 2014;11 Suppl 1:S105-12.

35. Hwang J, Kim YH. Physical activity and its related motivational attributes in adolescents with different BMI. Int J Behav Med. 2013;20(1):106-13.

36. Page A, Cooper AR, Stamatakis E, Foster LJ, Crowne EC, Sabin M, et al. Physical activity patterns in nonobese and obese children assessed using minuteby-minute accelerometry. Int J Obes (Lond). 2005;29(9):1070-6.

37. Deforche BI, De Bourdeaudhuij IM, Tanghe AP. Attitude toward physical activity in normal-weight, overweight and obese adolescents. J Adolesc Health. 2006;38(5):560-8.

38. Chung AE, Skinner AC, Steiner MJ, Perrin EM. Physical activity and BMI in a nationally representative sample of children and adolescents. Clin Pediatr (Phila). $2012 ; 51(2): 122-9$.

39. 2008 Physical Activity Guidelines for Americans: Be Active, Healthy, And Happy! : U.S. Department of Health and Human Services; 2008. p. 15-20.

40. Bai Y, Chen S, Laurson KR, Kim Y, Saint-Maurice PF, Welk GJ. The Associations of Youth Physical Activity and Screen Time with Fatness and Fitness: The 2012 NHANES National Youth Fitness Survey. PLoS One. 2016;11(1):e0148038.

41. Fakhouri TH, Hughes JP, Burt VL, Song M, Fulton JE, Ogden CL. Physical activity in U.S. youth aged 12-15 years, 2012. NCHS Data Brief. 2014(141):1-8. 
42. Kuczmarski RJ, Ogden CL, Guo SS, Grummer-Strawn LM, Flegal KM, Mei Z, et al. 2000 CDC Growth Charts for the United States: methods and development. Vital Health Stat 11. 2002(246):1-190.

43. Barlow SE. Expert committee recommendations regarding the prevention, assessment, and treatment of child and adolescent overweight and obesity: summary report. Pediatrics. 2007;120 Suppl 4:S164-92.

44. Ogden CL, Carroll MD, Kit BK, Flegal KM. Prevalence of obesity and trends in body mass index among US children and adolescents, 1999-2010. JAMA. 2012;307(5):483-90.

45. Grundy SM, Cleeman JI, Daniels SR, Donato KA, Eckel RH, Franklin BA, et al. Diagnosis and management of the metabolic syndrome: an American Heart Association/National Heart, Lung, and Blood Institute Scientific Statement. Circulation. 2005;112(17):2735-52.

46. Carson V, Staiano AE, Katzmarzyk PT. Physical activity, screen time, and sitting among U.S. adolescents. Pediatr Exerc Sci. 2015;27(1):151-9.

47. Heshmat R, Shafiee G, Kelishadi R, Babaki AE, Motlagh ME, Arefirad T, et al. Is the association of continuous metabolic syndrome risk score with body mass index independent of physical activity? The CASPIAN-III study. Nutr Res Pract. 2015;9(4):404-10.

48. Rendo-Urteaga T, de Moraes AC, Collese TS, Manios Y, Hagströmer M, Sjöström M, et al. The combined effect of physical activity and sedentary behaviors on a clustered cardio-metabolic risk score: The Helena study. Int $J$ Cardiol. 2015;186:186-95. 
49. Väistö J, Eloranta AM, Viitasalo A, Tompuri T, Lintu N, Karjalainen P, et al. Physical activity and sedentary behaviour in relation to cardiometabolic risk in children: cross-sectional findings from the Physical Activity and Nutrition in Children (PANIC) Study. Int J Behav Nutr Phys Act. 2014;11:55. 
Chapter Two: Review of the Literature 


\section{Metabolic Risk}

\section{Definition}

Metabolic syndrome (MetS) is defined by the American Heart Association/National Heart, Lung, and Blood Institute (AHA/NHLBI) as a cluster of unhealthy cardiovascular disease (CVD) risk factors including abdominal obesity, elevated blood pressure (BP), high levels of triglycerides (TG), low levels of high-density lipoprotein cholesterol (HDL-C), and elevated fasting plasma glucose (FPG) levels (1). Commonly used demarcation points for metabolic risk factors in children and adolescents have been based on a modified definition of MetS proposed originally by the Third Report of the National Cholesterol Education Program Expert Panel on Detection, Evaluation and Treatment of High Blood Cholesterol in Adults (NCEP ATP III) (2). The demarcation points for each individual criterion are waist circumference (WC) $\geq 90$ th percentile; systolic or diastolic $\mathrm{BP} \geq 90$ th percentile (age, height, and sex-specific); $\mathrm{TG} \geq$ $110 \mathrm{mg} / \mathrm{dL} ; \mathrm{HDL}-\mathrm{C} \leq 40 \mathrm{mg} / \mathrm{dL}$; and FPG concentration $\geq 100 \mathrm{mg} / \mathrm{dL}$. While these cutpoints have been utilized in the literature, there is no universal definition of MetS for children and adolescents.

A clustered metabolic risk (cMetS) score is a continuous variable which is derived by standardizing and then summing continuously distributed cardiometabolic components to create a z-score (3). A lower risk score is indicative of a healthier metabolic profile. Components which may be included in such a score include all components of the MetS, fasting insulin, homoeostasis model of assessment for insulin resistance (HOMA-IR), and various measures of body composition. The purpose of using the cMetS score as a continuous variable is to maximize statistical power given the relatively low prevalence 
of the MetS in adolescents.

\section{Estimated Prevalence in Adolescents}

It has been shown in a nationally representative sample of U.S. adolescents, aged 12-19, that the overall unweighted prevalence of abnormal BP, elevated TG, low HDL-C and elevated FPG are $4.9 \%, 20.6 \%, 16.1 \%$, and 16.5\%, respectively (4). Male adolescents, when compared to female adolescents, displayed a higher prevalence of MetS, and most individual metabolic risk factors. These data suggest that approximately one in 10 U.S. adolescents possess three or more MetS criteria and would be classified as having MetS.

Approximately three out of four U.S. adolescents do not meet the current physical activity $(\mathrm{PA})$ recommendations $(5,6)$. The relationship between PA and cMetS score in youth has been previously debated in the literature (7-17). Though several studies have consistently shown a significant inverse association between increased PA and cardiometabolic risk (7-14), some studies suggest that this relationship is mediated by adiposity (15-17). These studies will be further discussed in detail throughout this review of the literature. Details regarding study sample characteristics and statistical findings are presented in Table 1.

\section{The Independent Relationship between PA and Metabolic Risk}

\section{Clustered Metabolic Risk Score}

Earlier studies have demonstrated the independent relationship between cMetS score and PA (7-14). For example, Hong et al. (7) performed a cross-sectional analysis in 
a sample of 275 adolescents, aged 12-13 who were recruited from various elementary schools in the city of Suwon, South Korea. The sample included 130 boys and 145 girls, and included participants within various classes of body mass index (BMI), fitness and insulin resistance. Physical activity was assessed using the Kenz Lifecorder EX (18), which is a uniaxial accelerometer. Participants were asked to wear the device from the time they got up in the morning until they went to bed, except during bathing and showering, for seven full consecutive days. Blood samples were drawn from all subjects following an overnight fasting period of 10 hours. A clustered risk score was calculated, and the components included in the score were $\mathrm{WC}$, resting BP, TG, HDL-C and the homoeostasis model of assessment for insulin resistance (HOMA-IR). It was observed that only vigorous-intensity PA was a significant predictor of cMetS score, independent of age and Tanner scale (sexual maturation). While this same association was not significant with light- and moderate-intensity PA, it was observed in the study that those in the upper quartile of cMetS score performed significantly less PA, at all intensities, when compared to those in the lower quartile of cMetS score $(p<0.001)$. Due to the fact that WC was a factor used to calculate the clustered metabolic score, this analysis was not adjusted for adiposity.

Further support of this relationship was suggested by Pahkala et al. (8), who studied a sample of 13-year old adolescents $(n=542)$ recruited from an ongoing atherosclerosis prevention study in Turku, Finland. Leisure-time PA (LTPA) was assessed with a self-administered questionnaire, which had the participant self-report the frequency, duration and intensity of their LTPA. From this, a PA index was calculated as a multiple of resting metabolic rate, measured in MET hours per week (MET h/wk). 
Adolescents who performed $<5 \mathrm{MET} \mathrm{h/wk}$ of PA were compared to those who performed $\geq 5 \mathrm{MET} \mathrm{h/wk}$. The risk factors included in their cMetS score were BMI, HDL-C, TG and systolic and diastolic BP. Investigators reported higher levels of LTPA were significantly associated with a lower cMetS score, but only in girls (OR 0.65, CI 0.43-0.98, $\mathrm{p}=0.038$ ). Additional analyses were done comparing those who performed $<5$ MET h/wk to those who performed $>50$ MET h/wk of LTPA. When examining these extreme levels of LTPA, a significant association between PA and cMetS score was also observed in boys (OR 0.48, CI 0.22 to $0.99, \mathrm{p}=0.049)$. Neither of these analyses, however, were adjusted for BMI due to its inclusion in the cMetS score.

Stabelini Neto et al. (9) analyzed a random sample of Brazilian adolescents aged 10-18 $(n=391)$ enrolled in public and private schools in the city of Jacarezinho, Parana, Brazil. The objective of the study was to observe the associations between cMetS score and moderate to vigorous PA (MVPA), and to identify the amount of daily PA needed to prevent the development of various metabolic risk factors. Physical activity was measured with an Actigraph accelerometer (GT3X, Pensacola, Florida, USA) (19). Adolescents who obtained no less than four full days of data, including at least one weekend day, were included in the study. The cMetS score was comprised of the following components: BP, HDL-C, WC, FPG, and TG. There was a significant relationship between time spent in moderate-intensity PA and cMetS score $(r=-0.191$, $\mathrm{p}<0.01$ ). Vigorous PA was inversely associated with $\mathrm{WC}$, but no other associations were found.

In 2006, Ekelund et al. (10) used population-based data from three European regions of the 1997 and 2000 European Youth Heart Study $(n=1,921)$ to examine the 
relationship between PA and cMetS amongst adolescent boys and girls (9 to 10 and 15 to 16 years old). Physical activity was assessed using an MTI Actigraph accelerometer (19), which measured counts per minute (cpm) and was worn on the right hip over two weekdays and two weekend days. A continuous cMetS score was derived by standardizing and summing the following components: the sum of four skinfolds, BP (average of systolic and diastolic BP), FPG, fasting insulin, HDL-C, and TG. Physical activity was inversely associated with the cMetS score after adjustment for television viewing and other potential confounders $(\beta=-0.08, \mathrm{p}<0.0001)$. In an additional analysis, the score excluded adiposity and the model adjusted for the sum of four skinfolds as a confounding factor. Before and after this adjustment, it was demonstrated that there was a significant relationship between PA and cMetS score $(\beta=-0.09, \mathrm{p}<0.0001)$.

Ekelund et al. (11) conducted follow-up analyses to further examine data from the European Youth Heart Study, using participants of the same demographics discussed previously $(n=1,709)$. Physical activity was again measured via accelerometer, and cMetS score included the standardized summation of the same components, the only difference being that the estimate of adiposity was WC rather than skinfolds. Waist circumference was excluded in this score in models that adjusted for adiposity as a confounding factor to avoid collinearity; in this case, adiposity was once again modeled as skinfolds. It was observed that total PA was inversely associated with cMetS score, and the magnitude of this association remained unchanged following adjustment for WC $(\beta=-0.08,95 \%$ CI $-0.10,-0.05)$.

Also examining data from the European Youth Heart Study, Anderson et al. (12) observed that PA decreased the odds for cMetS score, even in overweight youth. Data 
from 1,732 nine and 15-year-old randomly selected youth were collected in a crosssectional analysis exploring the association between PA and clustered CVD risk factors. Physical activity was measured by an accelerometer worn on the right hip for four consecutive days (two weekdays and two weekend days). Risk factors comprising the cMetS score included systolic BP, TG, ratio of total cholesterol (TC) to HDL-C, HOMAIR score, sum of four skinfolds, and aerobic fitness $\left(\mathrm{VO}_{2} \mathrm{max}\right)$. Increased odds of a higher cMetS score were reported for those in the lowest quintile of PA [OR 3.29 (95\% CI 1.965.52)] compared to those in the highest [OR 1.00, referent]. Odds ratios in this analysis did not change when participants were stratified by weight status; therefore, regardless of weight status, higher levels of PA significantly lower odds of metabolic risk in youth.

In 2010, Okosun et al. (13) conducted a cross-sectional study, which utilized data from the 2003-2004 cycle of the continuous National Health and Nutrition Examination Survey (NHANES) (20). This data set is a nationally representative sample of the U.S. population. The study included adolescents between the ages of 12 and 17 who had data collected on all available variables and completed a minimum overnight fasting period of eight hours $(n=655)$. Physical activity was measured using self-reported data obtained by trained interviewers. Participants were asked the following questions: (1) During the past 30 days, did you do any vigorous activities for at least 10 minutes that caused heavy sweating or large increases in breathing or heart rate?; and, (2) During the past 30 days, did you do any tasks in or around your home or yard for at least 10 minutes that required moderate or greater physical effort? Respondents who answered no to vigorous activities, or who answered yes but did not give at least one vigorous activity or reported duration of less than 10 minutes, were recorded as sedentary. The same was approach was utilized 
when asking about moderate activities. Components included in the calculated cMetS score were: mean arterial pressure (MAP), TG, FPG, WC, and HDL-C. Investigators reported significant increases in cMetS score with decreasing reported intensities of LTPA. The mean cMetS scores for those whose LTPA was classified as sedentary, moderate, and vigorous were $0.88,0.17$ and -0.42 , respectively $(\mathrm{p}<0.001)$. Though an independent association was also observed between BMI and cMetS score, it was shown that vigorous LTPA was associated with significantly lower cMetS risk score within each BMI class (healthy weight, overweight, and obesity)( $<<0.05$ for all). Therefore, regardless of weight status, PA had a positive effect on clustered metabolic risk.

Recently, Machado-Rodrigues et al. (14) reported sex differences in the proposed relationship between PA and cMetS score. A cross-sectional study utilizing data from a sample of 924 randomly selected Brazilian youth aged 11-17 years was analyzed. In order to measure PA, participants were asked to keep a diary in which they recorded all activities and their respective intensities performed every 15 minutes. Intensity was selfreported by the participant on a scale of one to nine. Each number representing intensity was associated with specific values of caloric expenditure, which were used to estimate total daily energy expenditure. Each number was described and valued as follows: (1) sleeping or resting in bed: $0.26 \mathrm{kcal} / \mathrm{kg} / 15 \mathrm{~min}$; (2) sitting: $0.38 \mathrm{kcal} / \mathrm{kg} / 15 \mathrm{~min}$; (3) light activity standing: $0.57 \mathrm{kcal} / \mathrm{kg} / 15 \mathrm{~min}$; (4) slow walking (approx. $4 \mathrm{~km} / \mathrm{hr}$ ): 0.69 $\mathrm{kcal} / \mathrm{kg} / 15 \mathrm{~min}$; (5) light manual tasks: $0.84 \mathrm{kcal} / \mathrm{kg} / 15 \mathrm{~min}$; (6) leisure and recreational sports: $1.2 \mathrm{kcal} / \mathrm{kg} / 15 \mathrm{~min}$; (7) manual tasks at a moderate pace: $1.4 \mathrm{kcal} / \mathrm{kg} / 15 \mathrm{~min}$; (8) leisure and sport activities of higher intensity- not competitive: $1.5 \mathrm{kcal} / \mathrm{kg} / 15 \mathrm{~min}$; and (9) very intensive activities- competitive sports: $2.0 \mathrm{kcal} / \mathrm{kg} / 15 \mathrm{~min}$. The continuous 
cMetS score utilized included the standardization and summation of insulin, TG, FPG, HDL-C and BP. The results suggested that in girls, MVPA was significantly and inversely associated with cMetS score after adjustment for several potential confounders, including WC ( $\beta=-0.08,95 \% \mathrm{CI},-0.91$ to -0.8$)$. Waist circumference was shown to also be an independent predictor of cMetS score. In boys, however, MVPA was not significantly associated with cMetS score in the unadjusted regression model, or after adjustment for age and $\mathrm{WC}$.

To summarize, an independent relationship between PA and cMetS score has consistently been observed in the literature. The previously discussed studies all included males and females, participants were of similar age, and differing means of measuring PA (accelerometry and self-report) were utilized. While all studies were cross-sectional and of sufficient sample size, studies presented results produced by both linear and logistic regression models. Moreover, similar findings were produced in adolescent samples from different countries (Europe, U.S. and Brazil) with varying ethnicities.

\section{Individual Metabolic Components}

Some studies have reported significant relationships between PA and BP in children and adolescents, independent of adiposity $(11,14,21)$. In 2006, Ekelund et al. (11) demonstrated that after adjusting for the sum of four skinfolds, the inverse relationships between PA and both systolic and diastolic BP remained significant $(\mathrm{p}<0.001)$. Machado-Rodrigues et al. (14) observed that MVPA was inversely related to BP in both girls and boys ( $\mathrm{r}=-0.09, \mathrm{p}<0.05$ and $\mathrm{r}=-10, \mathrm{p}<0.05$, respectively). Furthermore, a meta-analysis was performed to observe the relationship between 
objectively measured PA and metabolic risk components, such as $\mathrm{WC}$, fasting insulin, TG, HDL_C, and resting systolic BP; over 20,000 participants aged four to 18 years were collected from various studies (21). It was reported that higher volumes of MVPA, but not total PA volume (TPAV), was significantly associated with lower systolic BP values following adjustment for age, sex, sedentary time and WC.

Some of the same studies have also shown that independent of adiposity, PA has a significant negative relationship with TG $(10,11,21)$. Ekelund et al. (11) observed that a significant inverse relationship was evident between PA and TG $(p=0.02)$, which was only slightly attenuated following adjustment for the sum of four skinfolds $(\beta=-0.06$, $\mathrm{p}<0.05)$. Data from the European Youth Heart Study (10) illustrated that TG concentration was negatively and significantly associated with moderate PA $(\beta=-0.05$, $\mathrm{p}<0.05)$ and TPAV $(\beta=-0.06, \mathrm{p}<0.05)$ after adjusting for WC. Additionally, the aforementioned meta-analysis of over 20,000 children and adolescents showed that TG concentration was significantly and inversely related to TPAV and time spent in MVPA ( $p<0.001$ for both) after adjusting for age, sex and WC (21).

The two previously discussed studies have also suggested a positive relationship between PA and HDL-C, independent of adiposity $(8,14)$. In the first, Pahkala et al. (8) found that in 13-year old boys, higher volumes of LTPA had a positive effect on HDL-C $(\beta=0.043, p=0.017)$, but not on other clustered metabolic risk factors. This remained significant after adjusting for BMI $(\mathrm{p}<0.05)$. In the second, Machado-Rodrigues et al. (14) observed that in Brazilian adolescent girls, MVPA was positively associated with HDL-C $(r=0.4, p<0.05)$. Additionally, Heshmat et al. (15) performed a cross-sectional analysis in 5,625 Iranian students between the ages of 10-18 in order to examine the 
potential associations of PA on interactions between excess body weight and cMetS score. The sample included participants from the third survey of the Childhood and Adolescence Surveillance and Prevention of Adult Non-Communicable Disease (CASPIAN) study conducted in 2009-2010. Leisure time PA was assessed using a validated questionnaire (22) and participants were categorized according to how many days per week they participated in PA outside of school. The PA question asked about activity which caused heavy sweating or large increases in breathing or heart rate for more than 30 minutes. The cMetS score calculated included the following components: WC, MAP, HDL-C, TG, and FPG. Despite suggesting that PA and cMetS score were not independently associated, it was found that in both sexes, LTPA was positively associated with HDL-C after adjusting for BMI $(\beta=0.16, \mathrm{p}<0.05)$.

Evidence also exists suggesting that FPG is affected by PA independent of weight status in children and adolescents $(10,11)$. In 2006, Ekelund et al. (11) demonstrated that the relationship between PA and FPG in European adolescents $(n=1921)$ remained significant $(\mathrm{p}<0.001)$ following adjustment for the sum of four skinfolds. A similar significant relationship was reported in a previously discussed follow-up analysis by Ekelund et al. (10) wherein fasting glucose was inversely associated with moderate, vigorous, and TPAV in European children and adolescents $(\beta=-0.11, p<0.001 ; \beta=-0.10$, $\mathrm{p}<0.001$; and $\beta=-0.11, \mathrm{p}<0.001$ in moderate, vigorous and TPAV, respectively). In summary, independent relationships between PA and individual components of the cMetS score (BP, TG, HDL-C and FPG) have been previously observed in the literature. Similar results were observed in studies utilizing comparable age ranges, differing means of measuring PA, and with samples of varying ethnic origin. 


\section{The Role of Adiposity in Mediating the Relationship between PA and Metabolic Risk}

Clustered Metabolic Risk Score

Conflicting evidence exists which suggests that the relationship between cMetS risk score and PA is mediated by adiposity (15-17). This idea would suggest that the association of PA and cMetS risk score is not independent, but instead reliant on the association between PA and adiposity. One could then assume that those who are active typically demonstrate more desirable cMetS risk profiles due to the benefits of maintaining a healthy weight as opposed to the physiological benefits of regular activity. In a cross-sectional study, Rendo-Urteaga et al. (16) examined the associations between independent and combined effects of PA and sedentary behavior (SB) with individual and clustered cardiometabolic risk factors. Participants included 769 adolescents (12.5-17.5 years) from the Healthy Life-style in Europe by Nutrition in Adolescence (HELENA) Study. Activity was determined using both self-report (questionnaires) and accelerometer data. A clustered cardiometabolic risk index was created using the following components: HOMA-IR index, systolic BP, TG, TC, HDL-C, $\mathrm{VO}_{2 \max }$ and the sum of four skinfolds. Regardless of the means of measurement, PA was not significantly associated with cMetS score in all analyses. There was an observed association between the combined effect of $\mathrm{PA}$ and $\mathrm{SB}$ on cardiometabolic risk (PA $\geq 60 \mathrm{~min} /$ day; $\mathrm{SB}<2 \mathrm{~h} /$ day), but this relationship was no longer significant $(\mathrm{p}>0.05)$ following adjustment for $\mathrm{WC}$ and other potential confounders (i.e. seasonality, maternal education level, sex, age, height, carbohydrate, proteins, lipids and total energy intake). 
Vaisto et al. (17) sought to observe the independent and combined associations of PA and SB with cardiometabolic risk in children. Their sample $(n=468)$ included six to eight year-old children from Finland who provided baseline data in the Physical Activity and Nutrition in Children (PANIC) Study between 2007 and 2009. Volumes and type of both habitual PA and SB were assessed by the PANIC Physical Activity Questionnaire. These reports were validated using the Actiheart monitor, which combines heart rate and accelerometer measurements $(r=0.37, p=0.033)$. A continuous cMetS score was derived from the sum of z-scores of the following factors: WC, insulin, FPG, TG, HDL-C, and the mean of systolic and diastolic BP. While it was found in their analysis that TPAV was significantly associated with cardiometabolic risk $(\beta=-0.135, \mathrm{p}<0.01)$ and fasting insulin $(\beta=-0.99, p<0.01)$, after adjusting for body fat percentage (DXA), these relationships were no longer significant $(\beta=-0.048, p=0.232$ and $\beta=-0.038, p=0.380$ for cardiometabolic risk and fasting insulin, respectively).

A previously discussed study by Heshmat et al. (15) also reported that although a relationship existed between LTPA and clustered MetS components $(\beta=1.13, \mathrm{p}<0.05)$, adjustment for BMI and screen time resulted in the loss of statistical significance $(\beta=1.10, p>0.05)$. It was also shown that BMI percentiles were associated with cMetS, independent of LTPA and screen time $(\beta=1.07, \mathrm{p}<0.05)$.

\section{Individual Metabolic Components}

Despite the previously discussed possibility of an independent relationship between PA and BP in adolescents, evidence also suggests that this relationship may be mediated by adiposity. Pahkala et al. (8) reported that LTPA was significantly inversely 
associated with systolic BP in Brazilian girls $(\beta=-1.78, \mathrm{SE}=0.88 ; \mathrm{p}<0.05)$. However, when BMI was included in the analysis, these findings were no longer significant $(\beta=-$ 1.07, $\mathrm{SE}=0.83 ; \mathrm{p}>0.05)$. In contrast, Heshmat et al. (15) reported that MAP was significantly positively associated with BMI percentile in Iranian adolescents, independent of LTPA. Percentiles were classified as follows: underweight $\left(\mathrm{BMI}<5^{\text {th }}\right.$ percentile of the study population), normal (5-84th percentile), overweight (85-94th percentile), and obese ( $>95$ th percentile). When analyzing the relationship between MAP and PA, there was no significance reported after BMI percentile was included in the model.

The potential mediating effect of weight status on the relationship between PA and TG has also been investigated in adolescents. In a cross-sectional analysis of 5,625 Iranian students between the ages of 10-18, Heshmat et al. (15) observed that there was no significant association found between LTPA and TG concentration $(p=0.08)$. Additionally, TG were significantly positively associated with BMI percentile, independent of LTPA $(\mathrm{p}<0.001)$.

The relationship between PA and HDL-C and their association with body weight has also been investigated in adolescents $(8,15)$. Pahkala et al. $(8)$ originally reported that LTPA was significantly associated with HDL-C in girls $(\beta=0.045, \mathrm{SE}=0.019 ; \mathrm{p}<0.05)$. However, when BMI was included in the analysis, these findings were no longer significant $(\beta=0.033, \mathrm{SE}=0.19 ; \mathrm{p}>0.05)$. Heshmat et al. (15) also reported that HDL-C was significantly inversely associated with BMI percentile, independent of LTPA $(\mathrm{p}<0.001)$. The same analysis, however, suggested that LTPA was positively associated with HDL-C after adjusting for BMI percentiles $(\mathrm{p}<0.001)$. Though significance 
remained when including BMI and LTPA in the same model, the relationship was no longer statistically significant after adjustment for the BMI and LTPA interaction term. Therefore, it can be inferred that the interaction between BMI and LTPA was mediating the initial relationship between LTPA and HDL-C.

It has been suggested in the literature that the relationship between FPG and PA is not independent of adiposity in adolescents. In support of this, Stabelini Neto et al. (9) performed a cross-sectional analysis which suggested that, though PA and cMetS score were significantly associated in adolescents $(\mathrm{p}<0.01)$, FPG individually was not significantly associated with light, moderate or vigorous PA. Overall, however, there is a paucity of data on the relationship between PA and FPG in adolescents.

\section{Summary}

While there is an abundance of literature demonstrating the relationship between PA and cMetS score, findings remain inconsistent. Some studies suggest that varying methods of measuring PA may lead to differences in outcomes. However, this idea is somewhat disproven by the fact that there are studies employing similar methods both supporting and invalidating the independent relationship between PA and cMetS score. Similar components were also utilized in the standardization and summation of cMetS score. Sufficient sample size and statistical power was also observed for both theories (that the relationship is either independent of, or mediated by, adiposity). Therefore, the current inconclusive evidence warrants further examination of the relationship between BMI, PA, and cMetS score. The future examination of this relationship may be done by studying the differences in cMetS score between adolescents through use of statistical 
models that have been categorized by PA and BMI. Accordingly, the potentially mediating role of PA, BMI, or both on increasing cardiometabolic risk could be elucidated. To our knowledge, a study such as this has not been performed using a nationally representative sample of U.S. adolescents. 
Table 1 Summary of studies examining the associations between BMI, PA and cMetS score in children/adolescents

\begin{tabular}{|c|c|c|c|c|c|c|}
\hline Publication & $\begin{array}{l}\text { Study Type and } \\
\text { Location/Survey }\end{array}$ & $\mathbf{n}$ & Ages (yr) & Measures & Findings & Comments \\
\hline \multirow[t]{3}{*}{ Hong, 2011 (7) } & $\begin{array}{l}\text { Cross-sectional } \\
\text { Suwon, South Korea }\end{array}$ & 275 & $\begin{array}{l}\text { Range 12-13 } \\
\text { years }\end{array}$ & $\begin{array}{l}\text { Physical Activity: } \\
\text { Kenz Lifecorder EX } \\
(18)\end{array}$ & $\begin{array}{l}\text { Vigorous-intensity physical } \\
\text { activity inversely associated } \\
\text { with cMetS score } \\
(\beta=-0.240, p<0.001)\end{array}$ & $\begin{array}{l}\text { Adjusted for age and } \\
\text { Tanner scale of sexual } \\
\text { maturation }\end{array}$ \\
\hline & & & & $\begin{array}{l}\text { cMetS score: WC, } \\
\text { resting BP, TG, } \\
\text { HDL-C, HOMA-IR }\end{array}$ & & $\begin{array}{l}\text { Did not adjust for } \\
\text { adiposity }\end{array}$ \\
\hline & & & & & & $\begin{array}{l}\text { Did not analyze } \\
\text { associations between } \\
\text { PA and individual } \\
\text { cMetS score } \\
\text { components }\end{array}$ \\
\hline Pahkala, 2012 (8) & $\begin{array}{l}\text { Cross-sectional } \\
\text { Turku, Finland }\end{array}$ & 542 & 13 years & $\begin{array}{l}\text { Physical Activity: } \\
\text { Self-administered } \\
\text { questionnaire data } \\
\text { used to estimate PA } \\
\text { index in MET h/wk } \\
\text { cMetS score: BMI, } \\
\text { systolic and diastolic } \\
\text { BP, TG, and HDL-C }\end{array}$ & $\begin{array}{l}\text { Leisure-time physical activity } \\
\text { inversely associated with cMetS } \\
\text { score in girls only } \\
\text { (OR } 0.65, \text { CI } 0.43-0.98, p=0.038 \text { ) } \\
\text { Leisure-time physical activity } \\
\text { was beneficially associated with } \\
\text { BMI, HDL-C, systolic BP and } \\
\text { HDL-C/total cholesterol in girls } \\
\text { and HDL-C in boys } \\
(p<0.05 \text { for all) }\end{array}$ & $\begin{array}{l}\text { Adjusted for age and } \\
\text { sex } \\
\text { Did not adjust for } \\
\text { adiposity }\end{array}$ \\
\hline Stabelini Neto, 2014 (9) & $\begin{array}{l}\text { Cross-sectional } \\
\text { Parana, Brazil }\end{array}$ & 391 & $\begin{array}{l}\text { Range 10-18 } \\
\text { years }\end{array}$ & $\begin{array}{l}\text { Physical Activity: } \\
\text { Actigraph } \\
\text { accelerometer (19) }\end{array}$ & $\begin{array}{l}\text { Moderate-intensity physical } \\
\text { activity inversely associated } \\
\text { with cMetS score } \\
(\mathrm{r}=-0.191, \mathrm{p}<0.01)\end{array}$ & $\begin{array}{l}\text { All models were } \\
\text { unadjusted }\end{array}$ \\
\hline
\end{tabular}


cMetS score: $\mathrm{WC}$, BP, TG, HDL-C, and FPG
Moderate-vigorous physical activity inversely associated with $B P$ and $W C$

$(\mathrm{r}=-0.139, \mathrm{p}<0.05)$ for $\mathrm{BP}$

$(r=-0.166, p<0.05)$ for $\mathrm{WC}$

\begin{tabular}{|c|c|c|c|c|c|c|}
\hline Ekelund, 2006 (10) & $\begin{array}{l}\text { Cross-sectional } \\
1997 \text { \& } 2000 \text { European Youth } \\
\text { Heart Study }\end{array}$ & 1,921 & $\begin{array}{l}\text { Ranges 9-10 } \\
\text { and } 15-16 \\
\text { years }\end{array}$ & $\begin{array}{l}\text { Physical Activity: } \\
\text { Actigraph } \\
\text { Accelerometer (19) } \\
\text { cMetS score: sum of } \\
\text { four skinfolds, BP, } \\
\text { TG, HDL-C, FPG, } \\
\text { and fasting insulin, }\end{array}$ & $\begin{array}{l}\text { Total physical activity inversely } \\
\text { associated with cMetS score } \\
\text { after adjusting for sum of four } \\
\text { skinfolds } \\
(\beta=-0.09, p<0.0001) \\
\text { Total physical activity inversely } \\
\text { associated with all individual } \\
\text { cMetS score components, except } \\
\text { sum of four skinfolds and HDL- } \\
\text { C } \\
(p<0.05 \text { for all) }\end{array}$ & $\begin{array}{l}\text { Adjusted for sex, age } \\
\text { group, study location, } \\
\text { sexual maturity, birth } \\
\text { weight, and parental } \\
\text { socioeconomic status } \\
\\
\text { Suggests relationship } \\
\text { between physical } \\
\text { activity and cMetS } \\
\text { score is independent } \\
\text { of adiposity }\end{array}$ \\
\hline Ekelund, 2007 (11) & $\begin{array}{l}\text { Cross-sectional } \\
1997 \& 2000 \text { European Youth } \\
\text { Heart Study }\end{array}$ & 1,709 & $\begin{array}{l}\text { Ranges } 9-10 \\
\text { and } 15-16 \\
\text { years }\end{array}$ & $\begin{array}{l}\text { Physical Activity: } \\
\text { Actigraph } \\
\text { Accelerometer (19) } \\
\text { cMetS score: WC, } \\
\text { BP, TG, HDL-C, } \\
\text { FPG, and fasting } \\
\text { insulin }\end{array}$ & $\begin{array}{l}\text { Total physical activity inversely } \\
\text { associated with cMetS score } \\
\text { before and after adjusting for } \\
\text { sum of four skinfolds } \\
(\beta=-0.08, p<0.001) \\
\text { Total physical activity inversely } \\
\text { associated with all individual } \\
\text { cMetS score components, except } \\
\text { WC and HDL-C } \\
\text { ( }<<0.05 \text { for all) }\end{array}$ & $\begin{array}{l}\text { Adjusted for age } \\
\text { group, sex and study } \\
\text { location } \\
\text { Suggests relationship } \\
\text { between physical } \\
\text { activity and cMetS } \\
\text { score is independent } \\
\text { of adiposity }\end{array}$ \\
\hline Andersen, 2006 (12) & $\begin{array}{l}\text { Cross-sectional } \\
\text { European Youth Heart Study }\end{array}$ & 1,732 & 15 years & $\begin{array}{l}\text { Physical Activity: } \\
\text { Actigraph } \\
\text { accelerometer (19) } \\
\text { cMetS score: sum of } \\
\text { four skinfolds, } \\
\text { systolic BP, TG, }\end{array}$ & $\begin{array}{l}\text { Total physical activity inversely } \\
\text { associated with cMetS score } \\
\text { before and after stratifying by } \\
\text { weight status } \\
\text { Most active quintile: ref } \\
4^{\text {th }} \text { quintile: (OR } 2.03 \text {, CI } 1.18 \text { - } \\
3.50 \text { ) }\end{array}$ & $\begin{array}{l}\text { Adjusted for age, sex, } \\
\text { and country } \\
\text { Suggests relationship } \\
\text { between physical } \\
\text { activity and cMetS } \\
\text { score is independent } \\
\text { of adiposity }\end{array}$ \\
\hline
\end{tabular}




\begin{tabular}{|c|c|c|c|c|c|c|}
\hline & & & & $\begin{array}{l}\text { TC/HDL-C, HOMA- } \\
\text { IR, and } \mathrm{VO}_{2} \max \end{array}$ & $\begin{array}{l}3^{\text {rd }} \text { quintile: (OR 2.51, CI 1.47- } \\
4.26 \text { ) } \\
2^{\text {nd }} \text { quintile: (OR } 3.13 \text {, CI } 1.87- \\
5.25 \text { ) } \\
\text { Least active quintile: (OR } 3.29 \text {, } \\
\text { CI 1.96-5.52) } \\
(\beta=-0.08, p<0.001 \text { ) } \\
\text { Total physical activity inversely } \\
\text { associated with all individual } \\
\text { cMetS score components, except } \\
\text { HDL-C } \\
(p<0.05 \text { for all) }\end{array}$ & \\
\hline Okosun, 2010 (13) & $\begin{array}{l}\text { Cross-sectional } \\
\text { 2003-2004 National Health } \\
\text { and Nutrition Examination } \\
\text { Survey (NHANES) }\end{array}$ & 655 & $\begin{array}{l}\text { Range 12-17 } \\
\text { years }\end{array}$ & $\begin{array}{l}\text { Physical activity: } \\
\text { Self-reported } \\
\text { questionnaire data } \\
\text { cMetS score: WC, } \\
\text { MAP, TG, HDL-C } \\
\text { and FPG }\end{array}$ & $\begin{array}{l}\text { Vigorous-intensity physical } \\
\text { activity inversely associated } \\
\text { with cMetS score in healthy } \\
\text { weight, overweight, and obese } \\
\text { adolescents } \\
(\mathrm{p}<0.05, \mathrm{p}<0.01 \text { and } \mathrm{p}<0.05 \text { for } \\
\text { healthy weight, overweight and } \\
\text { obese, respectively) } \\
\text { Total physical activity inversely } \\
\text { associated with all individual } \\
\text { cMetS score components, except } \\
\text { HDL-C } \\
(\mathrm{p}<0.05 \text { for all) }\end{array}$ & $\begin{array}{l}\text { Adjusted for age, } \\
\text { race/ethnicity, } \\
\text { household income, } \\
\text { child education, and } \\
\text { BMI } \\
\text { percentile*leisure- } \\
\text { time PA } \\
\text { Suggests relationship } \\
\text { between physical } \\
\text { activity and cMetS } \\
\text { score is independent } \\
\text { of adiposity }\end{array}$ \\
\hline $\begin{array}{l}\text { Machado-Rodrigues, } 2015 \\
\text { (14) }\end{array}$ & $\begin{array}{l}\text { Cross-sectional } \\
\text { Brazil }\end{array}$ & 924 & $\begin{array}{l}\text { Range 11-17 } \\
\text { years }\end{array}$ & $\begin{array}{l}\text { Physical activity: } \\
\text { Self-maintained } \\
\text { activity diary used to } \\
\text { estimate total daily } \\
\text { energy expenditure in } \\
\mathrm{kcal} / \mathrm{kg} / \mathrm{min} \\
\text { cMetS score: insulin, } \\
\text { TG, FPG, HDL-C } \\
\text { and BP }\end{array}$ & $\begin{array}{l}\text { Moderate-to-vigorous-intensity } \\
\text { physical activity inversely } \\
\text { associated with cMetS score } \\
\text { before and after adjusting for } \\
\text { WC in girls only } \\
(\beta=-0.08, C l-0.91--0.08)\end{array}$ & $\begin{array}{l}\text { Adjusted for age and } \\
\text { cardiorespiratory } \\
\text { fitness } \\
\text { Suggests relationship } \\
\text { between physical } \\
\text { activity and cMetS } \\
\text { score is independent } \\
\text { of adiposity in girls } \\
\text { only }\end{array}$ \\
\hline
\end{tabular}


Did not analyze

associations between

$\mathrm{PA}$ and individual

cMetS score

components

\begin{tabular}{ll}
\hline Heshmat, 2015 (15) & Cross-sectional \\
& 2009 \& 2010 Childhood and \\
& Adolescence Surveillance and \\
& Prevention of Adult Non- \\
& Communicable Disease \\
& (CASPIAN) survey
\end{tabular}

(CASPIAN) survey

\section{5,625 Range 10-18 Physical activity:}

Self-reported

questionnaire data

cMetS score: WC, MAP, HDL-C, TG and FPG
Rendo-Urteaga, 2015 (16) Cross-sectional 2006 \& 2007 Healthy Lifestyle in Europe by Nutrition in Adolescence (HELENA) Study

\begin{abstract}
Leisure-time physical activity inversely associated with $\mathrm{cMetS}$ score before adjusting for BMI; insignificant after adjusting for

\section{BMI}

$(\beta=-0.12, p>0.05)$

Leisure-time physical activity inversely associated with MAP z-score before adjusting for BMI; insignificant after adjusting for BMI

$(\beta=-0.05, p>0.05)$
\end{abstract}

Leisure-time physical activity positively associated with HDL-

$\mathrm{C}$ z-score before and after

adjusting for BMI

$(\beta=0.10, p<0.05)$
Adjusted for age, sex,

living place, family

history, parent's

education,

socioeconomic status, and screen time

Suggests relationship between physical activity and cMetS score is mediated by adiposity

\begin{tabular}{|c|c|}
\hline $\begin{array}{l}\text { Combined effect of physical } \\
\text { activity and sedentary behavior } \\
\text { inversely associated with cMetS } \\
\text { score before adjusting for WC; } \\
\text { insignificant after adjusting for } \\
\text { WC } \\
\text { (OR } 0.29, \mathrm{p}>0.05 \text { ) }\end{array}$ & $\begin{array}{l}\text { Adjusted for } \\
\text { seasonality, maternal } \\
\text { education level, sex, } \\
\text { age, height, and } \\
\text { carbohydrate, } \\
\text { proteins, lipids and } \\
\text { total energy intake }\end{array}$ \\
\hline $\begin{array}{l}\text { Combined effect of physical } \\
\text { activity and sedentary behavior } \\
\text { inversely associated with } \\
\text { TC/HDL-C before adjusting for }\end{array}$ & $\begin{array}{l}\text { Suggests relationship } \\
\text { between physical } \\
\text { activity and cMetS } \\
\text { score is nonexistent or }\end{array}$ \\
\hline
\end{tabular}




\begin{tabular}{|c|c|c|c|c|c|c|}
\hline & & & & & $\begin{array}{l}\text { WC; insignificant after } \\
\text { adjusting for WC } \\
(\beta=-0.19, p=0.38)\end{array}$ & $\begin{array}{l}\text { mediated by } \\
\text { adiposity }\end{array}$ \\
\hline Väistö, 2014 (17) & $\begin{array}{l}\text { Cross-sectional } \\
\text { Finland; Physical Activity and } \\
\text { Nutrition in Children (PANIC) } \\
\text { Study }\end{array}$ & 468 & $\begin{array}{l}\text { Range 6-8 } \\
\text { years }\end{array}$ & $\begin{array}{l}\text { Physical activity: } \\
\text { PANIC Physical } \\
\text { Activity } \\
\text { Questionnaire } \\
\text { cMetS score: WC, } \\
\text { insulin, FPG, TG, } \\
\text { HDL-C and the mean } \\
\text { of systolic and } \\
\text { diastolic BP }\end{array}$ & $\begin{array}{l}\text { Total physical activity inversely } \\
\text { associated with cMetS score } \\
\text { before adjusting for body fat } \\
\text { percentage (DXA); insignificant } \\
\text { after adjusting for body fat } \\
\text { percentage } \\
(\beta=-0.048, p=0.232) \\
\text { Total physical activity inversely } \\
\text { associated with insulin before } \\
\text { adjusting for body fat } \\
\text { percentage; insignificant after } \\
\text { adjusting for body fat } \\
\text { percentage } \\
(\beta=-0.038, p=0.380) \\
\text { Total physical activity } \\
\text { associated with TG and HDL-C } \\
\text { before and after adjusting for } \\
\text { body fat percentage } \\
(\beta=-0.143, p=0.002) \text { for TG } \\
(\beta=0.116, p=0.013) \text { for HDL-C }\end{array}$ & $\begin{array}{l}\text { Adjusted for age and } \\
\text { sex } \\
\text { Suggests relationship } \\
\text { between physical } \\
\text { activity and cMetS } \\
\text { score is nonexistent or } \\
\text { mediated by } \\
\text { adiposity }\end{array}$ \\
\hline
\end{tabular}

Abbreviations: BMI, body mass index; PA, physical activity; cMetS, clustered metabolic risk; WC, waist circumference; BP, blood pressure; TG, triglyceride; HDL-C, highdensity lipoprotein cholesterol; HOMA-IR, homeostatic model assessment of insulin resistance; FPG, fasting plasma glucose; TC, total cholesterol. 


\section{References}

1. Grundy SM, Cleeman JI, Daniels SR, Donato KA, Eckel RH, Franklin BA, et al. Diagnosis and management of the metabolic syndrome: an American Heart Association/National Heart, Lung, and Blood Institute Scientific Statement. Circulation. 2005;112(17):2735-52.

2. Ford ES, Li C, Cook S, Choi HK. Serum concentrations of uric acid and the metabolic syndrome among US children and adolescents. Circulation. 2007;115(19):2526-32.

3. Eisenmann JC, Laurson KR, DuBose KD, Smith BK, Donnelly JE. Construct validity of a continuous metabolic syndrome score in children. Diabetology \& metabolic syndrome. 2010;2:8.

4. Miller JM, Kaylor MB, Johannsson M, Bay C, Churilla JR. Prevalence of metabolic syndrome and individual criterion in US adolescents: 2001-2010 National Health and Nutrition Examination Survey. Metab Syndr Relat Disord. 2014;12(10):527-32.

5. Dentro KN, Beals K, Crouter SE, Eisenmann JC, McKenzie TL, Pate RR, et al. Results from the United States' 2014 report card on physical activity for children and youth. J Phys Act Health. 2014;11 Suppl 1:S105-12.

6. Fakhouri TH, Hughes JP, Burt VL, Song M, Fulton JE, Ogden CL. Physical activity in U.S. youth aged 12-15 years, 2012. NCHS Data Brief. 2014(141):1-8.

7. Hong HR, Cho JK, Lee JY, Park JK, Kang HS. Clustering of metabolic syndrome risk factors associated with lifestyle factors and serum leptin in Korean children. Pediatr Exerc Sci. 2011;23(2):270-80. 
8. Pahkala K, Heinonen OJ, Lagström H, Hakala P, Hakanen M, Hernelahti M, et al. Clustered metabolic risk and leisure-time physical activity in adolescents: effect of dose? Br J Sports Med. 2012;46(2):131-7.

9. Stabelini Neto A, de Campos W, Dos Santos GC, Mazzardo Junior O. Metabolic syndrome risk score and time expended in moderate to vigorous physical activity in adolescents. BMC Pediatr. 2014;14:42.

10. Ekelund U, Brage S, Froberg K, Harro M, Anderssen SA, Sardinha LB, et al. TV viewing and physical activity are independently associated with metabolic risk in children: the European Youth Heart Study. PLoS Med. 2006;3(12):e488.10.

11. Ekelund U, Anderssen SA, Froberg K, Sardinha LB, Andersen LB, Brage S, et al. Independent associations of physical activity and cardiorespiratory fitness with metabolic risk factors in children: the European youth heart study. Diabetologia. 2007;50(9):1832-40.

12. Andersen L, Harro M, Sardinha L, Froberg K, Ekelund U, Brage S, et al. Physical activity and clustered cardiovascular risk in children: a cross-sectional study (the European Youth Heart Study). Lancet. 2006(368):299-304.

13. Okosun IS, Boltri JM, Lyn R, Davis-Smith M. Continuous metabolic syndrome risk score, body mass index percentile, and leisure time physical activity in American children. J Clin Hypertens (Greenwich). 2010;12(8):636-44. 
Chapter Three: Methodology 
The purpose of this study was to examine clustered metabolic risk (cMetS) in adolescents who participated in the National Health and Nutrition Examination Survey (NHANES) and were classified as not overweight/active (NOA), not overweight/not active (NONA), overweight/active (OA), or overweight/not active (ONA). Analysis was performed in the overall sample, and also stratified by sex. Weight status was determined using age- and sex-specific body mass index (BMI) percentiles (1), and activity was defined by either meeting or not meeting the federal aerobic physical activity (PA) recommendations for adolescents, which is $\geq 60$ minutes/day of moderate-to-vigorous PA (2). These categories were defined by the following cut-points:

NOA: $\mathrm{PA} \geq 60$ minutes/day; $\mathrm{BMI}<85$ th percentile

NONA: PA $<60$ minutes/day; BMI $<85$ th percentile

OA: $\mathrm{PA} \geq 60$ minutes/day; $\mathrm{BMI} \geq 85$ th percentile

ONA: PA $<60$ minutes/day; $\mathrm{BMI} \geq 85$ th percentile

The standardized risk factors in the calculated cMetS score were criteria included in the adolescent-specific modified definition of metabolic syndrome (MetS) as defined by the Third Report of the National Cholesterol Education Program Expert Panel on Detection, Evaluation and Treatment of High Blood Cholesterol in Adults (NCEP ATP III) (3). The following section expounds upon the methodology utilized in answering the proposed research questions.

\section{Sample}

The total sample size of survey participants ages two months and older was 30,442 for the 2007-2012 NHANES. The final sample consisted of 875 adolescents $12-17$ 
years of age who attended the morning examination session in the mobile examination center (MEC) following a minimum overnight fasting period of nine hours. Participants were excluded from the analysis if any of the variables of interest had "Missing" responses, or responses such as "Don't know" or "Refused", and females were excluded if they were pregnant.

The original 2007-2012 NHANES dataset included 30,442 children, adolescent and adult participants (Figure 1). A total of 2,944 participants were between the ages of 12 and 17. After applying a six-year fasting weight, the sample size decreased to 1,156 . After additional adjustments removing those with missing PA questionnaire data this sample was further reduced to 979 adolescents. Two additional participants were lost after removing those with missing data for BMI. None of the 977 adolescents were missing data on age, sex or race/ethnicity. Following exclusion of participants with missing triglyceride (TG), high-density lipoprotein cholesterol (HDL-C), and fasting plasma glucose (FPG) data the study sample included 963 adolescents. Lastly, adolescents with incomplete mean arterial pressure (MAP) data were excluded, and the final sample consisted of 875 adolescents. Excluding those who were currently pregnant had no effect on the final sample size after exclusion for all other variables of interest. 
Figure 1 Flow chart of sample inclusion.

Children, adolescent and adult participants in 2007-2012 NHANES

$$
\mathrm{n}=30,442
$$

$\longrightarrow \longrightarrow$\begin{tabular}{ll} 
EXCLUDED $($ Total $=27,498):$ \\
1. & Aged $<12$ years $(\mathrm{n}=8,879)$ \\
2. & Aged $>17$ years $(\mathrm{n}=18,619)$ \\
\hline
\end{tabular}

Adolescent participants in 2007-2012

NHANES aged 12-17

$\mathrm{n}=2,944$

FASTING WEIGHT APPLIED:

1. Lost to FA6YR $(n=1,788)$

Weighted sample of adolescent participants in 2007-2012 NHANES aged 12-17 $\mathrm{n}=1,156$

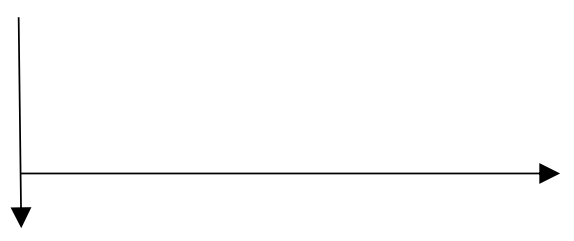

MISSING DATA $($ Total $=281)$

1. PA Questionnaire Data $(\mathrm{n}=177)$

2. $\quad$ BMI Data $(\mathrm{n}=2)$

3. Laboratory Data $(n=14)$

4. $\quad$ MAP Data $(\mathrm{n}=88)$

Final weighted sample of adolescent participants in 2007-2012 NHANES aged 12-17 with complete data $\mathrm{n}=875$

\section{Data Collection}

The study utilized six years of data from the 2007-2012 NHANES. The NHANES is a nationally representative, continuous survey, which consists of questionnaire data and 
physical measurements (4). In-home questionnaires are administered first, followed by a physical examination performed at the MEC. Complex, multistage probability sampling was utilized to select a randomized sample representative of the United States (U.S.) civilian, noninstitutionalized, resident population. The NHANES is designed to oversample population subgroups such as Hispanic, non-Hispanic black, non-Hispanic white and Other persons at or below $130 \%$ of the federal poverty level, and non-Hispanic white and Other persons aged 80 and over; the years 2011-2012 also included the oversampling of non-Hispanic Asian persons. This is done in order to increase the reliability and precision of health estimates for these particular subsamples.

\section{Sampling Design}

The complex sampling design utilized by the NHANES involves four stages.

First, primary sampling units (PSUs) are selected, typically being the equivalent of individual counties or clusters of small counties. Next, segments within these counties are selected; these may be as large as a city block or small group of blocks containing households. Third, individual dwelling units (DUs), or households, are randomly selected within each PSU segment. Lastly, individuals within each household are randomly selected to participate in the NHANES.

As previously mentioned, oversampling of specified populations is done to improve analyses for these subgroups. Weighting of sample data is a necessary procedure which aims to produce estimates of the statistics which would have been obtained had the entire population been measured. A sample weight is essentially the measure of the number of persons represented by a single survey participant. For example, if the 
sampling rate is $1 / 500$, each survey participant would represent 500 people. The NHANES sample weights are designed to achieve the following objectives: 1) compensate for probabilities of selection that may differ by race and Hispanic origin, income, sex, and age; 2) reduce bias arising from the potential differences between nonrespondents and respondents; 3) adjust data to correlate with an independent U.S. 2000 Census Bureau estimate of population totals; 4) remedy potential inadequacies in the sampling frame; and 5) minimize variances in the estimation procedure by utilizing highly accurate auxiliary information. A six year weight was created for the sub-sample of participants who attended the MEC after a 9-hour fasting period. Three cycles, or six years of data, collected from 2007-2010 were merged using SAS 9.4 (5). The necessary fasting weight (FA6YR) was applied to the total data set. When utilizing the survey cycle variable (SDDSRVYR), 6=2007-2008, 7=2009-2010, and 8=2011-2012. The sample weight was created in SAS using the following coding:

\section{If sddsrvyr in $(5,6,7)$ then FA6YR=1/3 *WTSAF2YR; ***2007-2012***;}

\section{Study Measures}

\section{Dependent measure(s): Clustered metabolic risk score}

The dependent variable in this analysis was a continuous clustered metabolic risk (cMetS) score. The cMetS score was derived by standardizing and then summing the zscores for the following cardio-metabolic components to create a summary z-score: MAP, FPG, HDL-C and TG. Each of these variables, with the exception of HDL-C, are directionally the same in that higher values are indicative of poorer metabolic health. Due to the fact that lower HDL-C values are considered less desirable, HDL-C z-score was 
inversed to match the directionality of the other variables. Ultimately, a higher overall cMetS score is indicative of poorer metabolic health.

The mean and standard deviation of each variable was calculated for the entire sample ( $\mathrm{n}=875$ ). The following coding was then utilized to calculate cMetS score for each individual in the sample:

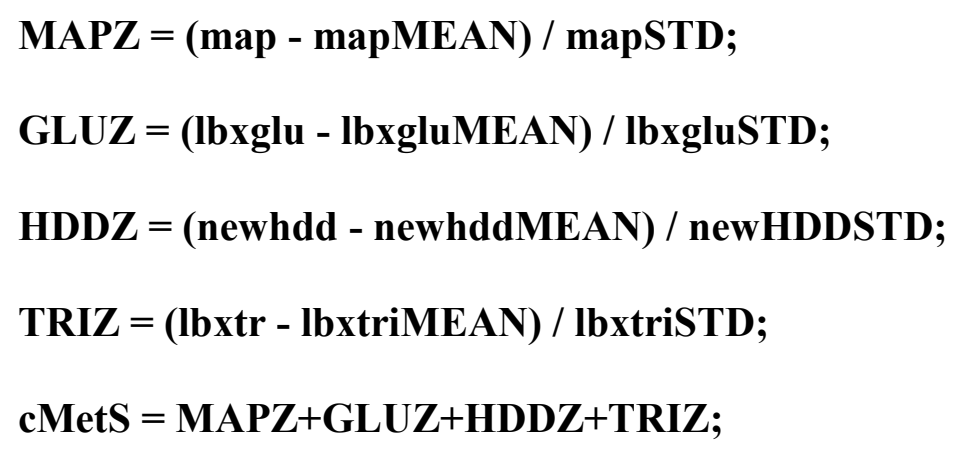

Fasting plasma glucose, HDL-C and TG concentration were measured using a Roche Modular P chemistry analyzer (6). Blood samples during the years 2007-2010 were processed at the University of Washington, Seattle, WA. Blood samples during the 2011-2012 cycle were processed, stored and shipped to the University of Minnesota, MN. Blood pressures (BP) were measured for all participants aged eight and above by certified BP examiners at the MEC. Participants rested quietly for five minutes, at which point three consecutive blood pressure readings were obtained. The mean of the second and third BP readings was used in the analysis. Calculating MAP was done utilizing the following equation: $\mathrm{MAP}=[(2 \mathrm{x}$ diastolic blood pressure $)+$ systolic blood pressure $] / 3$. 
The primary independent variables were dichotomized in order to provide a means of observing the potential combined and independent effects of each. The adolescents comprising the study sample were divided into one of four mutually exclusive categories: NOA (PA $\geq 60$ minutes/day; BMI $<85$ th percentile); NONA (PA $<$ 60 minutes/day; $\mathrm{BMI}<85$ th percentile); $\mathrm{OA}(\mathrm{PA} \geq 60$ minutes/day; $\mathrm{BMI} \geq 85$ th percentile); and $\mathrm{ONA}(\mathrm{PA}<60$ minutes/day; $\mathrm{BMI} \geq 85$ th percentile). In all analyses, the NOA group was the referent. Categories were defined to dichotomize activity level and weight status.

Physical activity level was determined using self-report interview data. The sample provided responses to the following questionnaire file items:

PAQ670: "In a typical week, on how many days $\{$ do you/does SP\} do moderateintensity sports, fitness, or recreational activities?"

PAD675: "How much time \{do you/does SP\} spend doing moderate-intensity sports, fitness, or recreational activities on a typical day?"

PAQ655: "In a typical week, on how many days $\{$ do you/does SP $\}$ do vigorousintensity sports, fitness, or recreational activities?"

PAD660: "How much time $\{$ do you/does SP\} spend doing vigorous-intensity sports, fitness, or recreational activities on a typical day?”

For participants 16 years of age and older, the questions were asked in home, by trained interviewers, using the Computer-Assisted Personal Interviewing (CAPI) system. For participants aged 12 to 15 , they were asked at the MEC by trained interviewers using the CAPI system. None of the 2007-2012 NHANES participants aged 12 years and older required a proxy respondent. The NHANES PA questionnaire is an adapted form of the 
Global Physical Activity Questionnaire (GPAQ) developed by the World Health Organization (WHO) (7). Previous research demonstrates that moderate agreement exists between the GPAQ and accelerometry-determined activity data $(\mathrm{r}=0.48)$, and in a study including data from nine different countries, it was concluded that the GPAQ is a generally acceptable instrument for estimating PA in population health surveillance systems (7-8).

Average minutes of moderate-vigorous PA per day were determined for each participant by first multiplying average minutes per day and average days per week, and then dividing this quantity by seven. Participants were considered "Active" if their average minutes per day were $\geq 60$, which coincides with meeting the daily federal PA recommendation for adolescents (2).

Weight status was determined using BMI, which is calculated by the NHANES using the following equation: $\mathrm{BMI}=($ weight in kilograms $) /(\text { height in } \mathrm{m})^{2}$. A participant was considered "Overweight" if their BMI was at or above the 85 th percentile (age- and sexspecific) (9). Body measurement data were obtained for each participant in the MEC by trained health technicians.

\section{Other Independent Measures}

$\underline{\text { Age }}$

Analyses in the present study were adjusted for age to account for any age differences in the potential associations being observed. Demographic data, such as age, sex, and race/ethnicity, were collected at the time of the in-home interview utilizing the CAPI 
program. Age in years was reported for all survey participants 79 years of age and younger. Individuals identified as 80 years and older are top coded at 80 years of age. $\underline{\operatorname{Sex}}$

Sex-adjusted and sex-stratified analyses were performed to 1) control for sex as a potential confounder and 2) identify any potential differences in associations between males and females.

$\underline{\text { Race/Ethnicity }}$

All analyses were adjusted for race/ethnicity. Participants were classified into one of five race/ethnic groups as defined by the 2007-2012 NHANES. The categories were: Mexican American, Other Hispanic, non-Hispanic white, non-Hispanic black, and nonHispanic Other Race- Including Multi-Racial. When subgroups of race/ethnicity were analyzed in the present study, the Mexican American and Other Hispanic subgroups were combined per the recommendation of the NHANES analytic note citing insufficient sample size in Other Hispanic adolescents (9).

\section{Data Analysis}

The data were initially managed in SAS 9.4 (5). Variable recoding was performed as well as data coding validation. Linear regression of the overall sample was performed in SAS, using PROC SURVEYREG, to observe the continuous relationship between cMetS score (dependent variable) and categorization based on PA and BMI. A fasting sampling weight was applied in all analyses, ultimately ensuring that the final sample was nationally representative of the U.S. adolescent population aged 12-17. Linear regression models, which observed the overall sample, were adjusted for age, sex and race/ethnicity. 
Sex-stratified models were adjusted for age and race/ethnicity only. The contributions of age, sex and race/ethnicity in the overall model were significant $(p<0.0001, p=0.0016$ and $\mathrm{p}=0.0107$ for age, sex, and race/ethnicity, respectively).

\section{Limitations}

The present study is not without limitations. First, due to the cross-sectional nature of the study, causality cannot be inferred. It should also be noted that findings can only be applied to a cMetS score comprised of the same variables as in the present study; using another set of variables could potentially produce a different relationship. Additionally, due to the fact that PA levels were measured via self-report, volumes and intensities of PA are subject to recall and report bias. Finally, all self-report data may be susceptible to the social desirability effect (i.e., participant answering questions with responses they feel the interviewers may want to hear or deem favorable).

\section{Summary}

The primary aims of this study are as follows: (1) examine the associations between meeting the daily federal PA recommendation, body mass, and metabolic risk score in U.S. adolescents; and (2) examine potential differences in the previously proposed aim between males and females. To our knowledge, this is the first study to examine cMetS scores among U.S. adolescents, categorized by PA and BMI, utilizing a nationally representative sample and to examine potential effect modification by sex for this association. 


\section{References}

1. Kuczmarski RJ, Ogden CL, Guo SS, Grummer-Strawn LM, Flegal KM, Mei Z, et al. 2000 CDC Growth Charts for the United States: methods and development. Vital Health Stat 11. 2002;(246):1-190.

2. 2008 Physical Activity Guidelines for Americans: Be Active, Healthy, And Happy!

U.S. Department of Health and Human Services. 2008;7-20.

3. Grundy SM, Cleeman JI, Daniels SR, Donato KA, Eckel RH, Franklin BA, et al.

Diagnosis and management of the metabolic syndrome: an American Heart

Association/National Heart, Lung, and Blood Institute Scientific Statement. Circulation. $2005 ; 112(17): 2735-52$.

4. United States Department of Health and Human Services. The National Health and Nutrition Examination Survey. 2016.

5. SAS Institute Inc 2013. Base SAS 9.4 Base Product, Cary, NC: SAS Institute Inc.

6. National Health and Nutrition Examination Survey 2011-2012. Laboratory Procedure Manuals. NCHS (National Center for Health Statistics). Atlanta, GA: Centers for Disease Control and Prevention, National Center for Health Statistics. 2013. https://www.cdc.gov/ nchs/nhanes/nhanes2011-2012/lab_methods_11_12.htm [Accessed 26 February 2017]. 7. Cleland CL, Hunter RF, Kee F, Cupples ME, Sallis JF, \& Tully, MA. Validity of the global physical activity questionnaire (GPAQ) in assessing levels and change in moderate-vigorous physical activity and sedentary behaviour. BMC Public Health. 2014;141255. DOI: 10.1186/1471-2458-14-1255. 
8. Bull FC, Maslin TS, \& Armstrong T. (2009). Global Physical Activity Questionnaire (GPAQ): Nine Country Reliability and Validity Study. J Phys Act Health. 2009;6(6):790804.

9. Centers for Disease Control and Prevention (CDC). National Center for Health Statistics (NCHS). National Health and Nutrition Examination Survey Analytic and Reporting Guidelines. U.S. Department of Health and Human Services, Center for Disease Control and Prevention, ed. 2006.

https://www.cdc.gov/nchs/data/nhanes/nhanes_03_04/nhanes_analytic_guidelines_ dec_2005.pdf [Accessed 26 February 2017]. 
Chapter Four: Physical Activity, Body Mass Index and Clustered Metabolic Risk In U.S. Adolescents: 2007-2012 NHANES. 
Objectives To examine variation in clustered metabolic risk (cMetS) in adolescents classified as not overweight/active (NOA), not overweight/not active (NONA), overweight/active (OA), and overweight/not active (ONA).

Background While studies to date have shown that children and adolescents who meet the current PA recommendations and maintain a healthy body weight demonstrate significantly lower cardiometabolic risk, there are some studies that suggest the relationship between PA and metabolic risk may be mediated by adiposity.

Methods The sample included adolescent participants ( $\mathrm{n}=875 ; 12-17$ years) of the 2007-2012 National Health and Nutrition Examination Survey (NHANES). The cMetS score included triglycerides, high-density lipoprotein cholesterol, fasting plasma glucose, and mean arterial pressure. Age- and sex-specific body mass index (BMI) percentiles were utilized; overweight was defined as BMI percentile $\geq 85^{\text {th }}$. Activity data included self-reported frequency of moderate-to-vigorous physical activity (PA). Adolescents reporting $\geq 60 \mathrm{~min} /$ day of PA were considered "active". General linear models, adjusted for age, sex, and race-ethnicity, were used. A six-year fasting sample weight was applied to the analyses in order to ensure representativeness of the data.

Results The cMetS scores were significantly $(\mathrm{p}<0.05)$ higher in OA and ONA adolescents when compared to $\mathrm{NOA}$ ( $\beta=1.08$ and $\beta=1.57$, respectively). In ONA males, cMetS was significantly $(\mathrm{p}<0.01)$ higher when 
compared to NOA males. In OA and ONA females, cMetS scores were significantly higher compared to the referent group ( $\mathrm{p}<0.01$ for both).

Conclusions The cMetS scores were higher in OA and ONA adolescents when compared to those classified as NOA. Whereas only ONA males demonstrated significantly higher cMetS score when compared to the NOA referent, both OA and ONA cMetS scores (vs NOA) were significantly higher in females. 


\section{Introduction}

Habitual physical activity (PA) among children and adolescents significantly improves cardiovascular and metabolic disease risk profiles (1-3) and reduces the risk for a number of comorbid conditions in adulthood $(1,4)$. Adiposity is also a strong predictor of undesirable health in adolescence (5-7), and is significantly associated with unfavorable outcomes in adulthood, including obesity, increased risk of developing cardiovascular disease (CVD), and premature mortality (7-9). Metabolic syndrome (MetS) is an unhealthy clustering of CVD risk factors which is defined as meeting at least three of the following five criteria: abnormal blood pressure (BP), elevated fasting plasma glucose (FPG), low high-density lipoprotein cholesterol (HDL-C), elevated triglycerides (TG), and augmented waist circumference (WC) (10). Along with the rise in obesity, MetS prevalence has also increased. In 1999-2002 4.1\% of adolescents had MetS (11) as compared to $10.1 \%$ in $2001-2010$ (12).

Clustered metabolic risk (cMetS score) is often represented by a continuous zscore, which commonly takes into account CVD risk factors, such as the components of MetS. Physical activity and healthy body weight have both been shown to be independently correlated with lower metabolic risk in all age groups $(5,13-19)$. While studies to date have shown that children and adolescents who meet the current PA recommendations and maintain a healthy body weight demonstrate significantly lower cardiometabolic risk (13-17), there are some studies that suggest the relationship between PA and metabolic risk may be mediated by adiposity (18-19). Recent literature suggests that approximately three out of four adolescents are currently meeting the federal PA recommendation (20). To our knowledge, the combined impact of PA and body mass 
index (BMI) on the cMetS score has yet to be examined in an analysis using a nationally representative sample of U.S. adolescents. The present study will add to existing literature not only by potentially identifying an important public health focus (PA, adiposity or both), but also by determining whether the health focus should differ depending on sex.

\section{Methods}

This study utilized six years of data from the 2007-2012 NHANES, a continuous survey conducted by the National Center for Health Statistics (21). The NHANES is a stratified multistage probability sample of the civilian non-institutionalized population of the U.S. The sample included adolescents 12-17 years of age who attended the morning examination session in the mobile examination center (MEC) following a minimum overnight fasting period of nine hours. The study included males $(\mathrm{n}=450)$ and nonpregnant females $(n=425)$ who had complete data on all variables of interest. The original 2007-2012 NHANES dataset included a total of 2,944 participants between the ages of 12 and 17. After applying a six-year fasting weight, the sample size decreased to 1,156. Additional adjustments removing those with missing data for the PA questionnaire, BMI, TG, HDL-C, FPG and MAP resulted in a final analytic sample of 875 adolescents.

\section{Physical Activity}

Physical activity level was determined using self-report interview data (22). For participants 16 years of age and older, the questions were asked in their home by trained 
interviewers using the Computer-Assisted Personal Interviewing (CAPI) system.

Participants aged 12 to 15 were interviewed in the MEC by trained interviewers using the CAPI system. Proxy respondents were not required for any of the 2007-2012 NHANES participants aged 12 years and older. The sample provided responses to the PA questionnaire file items PAQ 670 ("In a typical week, on how many days \{do you/does SP\} do moderate-intensity sports, fitness, or recreational activities? ") and PAD 675 ("How much time $\{$ do you/does SP\} spend doing moderate-intensity sports, fitness, or recreational activities on a typical day?”). Responses were also provided for identical questions referring to vigorous-intensity recreational activities (PAQ 655 and PAQ 660). Average minutes of moderate-vigorous PA per day was determined for each participant; this was calculated by first multiplying average minutes per day and average days per week of moderate and vigorous PA, then dividing this quantity by seven (23). Participants were considered "Active" if their average minutes per day were $\geq 60$ and "Not Active" if their average minutes per day were $<60$, which coincides with meeting and not meeting the daily federal PA recommendation for adolescents, respectively (24).

\section{Body Mass Index}

Weight status was determined using body mass index $[\mathrm{BMI}=($ weight in kilograms) / (height in m) ${ }^{2}$. Participants were considered "Not Overweight" if BMI < 85th percentile (age- and sex-specific), and "Overweight" if BMI $\geq 85$ th percentile. Anthropometric data were obtained for adolescent participants in the MEC by trained health technicians (22). 


\section{Clustered Metabolic Risk}

A cMetS score was created by standardizing and then summing the following continuously distributed cardio-metabolic components to create a z-score: MAP, FPG, HDL-C, and TG. The mean and standard deviation of each variable was calculated for the entire sample. Each of these variables, with the exception of HDL-C, are directionally the same in that higher values are indicative of poorer metabolic health. Due to the fact that lower HDL-C values are considered less desirable, HDL-C z-score was inversed to match the directionality of the other variables. Ultimately, a higher overall cMetS score is indicative of poorer metabolic health. The purpose of using a continuously distributed variable is to maximize statistical power.

Blood pressures were measured for all participants aged eight and above by certified BP examiners in the MEC. Participants rested quietly for five minutes and three consecutive blood pressure readings were obtained. The mean of the second and third BP

readings was used in the analysis. Calculating MAP was done in SAS using the following equation: $\mathrm{MAP}=[(2 \mathrm{x}$ diastolic blood pressure $)+$ systolic blood pressure $] / 3$. Concentrations of FPG, HDL-C and TG were measured using a Roche Modular P chemistry analyzer (25). Blood samples during the years 2007-2010 were processed at the University of Washington, Seattle, WA. Blood samples during the 2011-2012 cycle were processed, stored and shipped to the University of Minnesota, MN.

\section{$\underline{\text { Statistical Analysis }}$}

The data were managed utilizing SAS 9.4 (26), with subsequent analyses performed using PROC SURVEYREG. Analyses were adjusted for age, sex and 
race/ethnicity. Sex-stratified models were adjusted for age and race/ethnicity only. Participants were classified into one of five race/ethnic groups as defined by the 20072012 NHANES. The categories were: Mexican American, Other Hispanic, non-Hispanic white, non-Hispanic black, and non-Hispanic Other Race- Including Multi-Racial. When subgroups of race/ethnicity were analyzed, the Mexican American and Other Hispanic subgroups were combined per the recommendation of the NHANES analytic note citing insufficient sample size in Other Hispanic adolescents (27). This group is identified in the present study as "Hispanic".

A six-year fasting sample weight was created and applied to the analyses (If sddsrvyr in $(5,6,7)$ then FA6YR $=1 / 3 *$ WTSAF2YR). Overall and sex-stratified linear regression was performed to observe the continuous relationship between cMetS score in adolescents classified as NOA, NONA, OA, and ONA.

\section{Results}

A total of 875 adolescents aged 12-17 were included in the analysis after applying the fasting weight and excluding those who did not attend the MEC, were pregnant, or were missing data on variables of interest. Within the weighted population, $48.8 \%$ were male and $51.2 \%$ were female. The adolescent population was comprised of approximately $58.9 \%$ non-Hispanic Whites, $19.9 \%$ Hispanics, $15.5 \%$ non-Hispanic Blacks, and 5.7\% non-Hispanic Other Race-including Multi-Racial. Further demographic characteristics in males and females are demonstrated in Table 1. 
Table 1. Sample Demographic Characteristics of U.S. Adolescents Aged 12-17 (Weighted), Stratified by Sex $(n=875)$.

\begin{tabular}{clccc|c} 
& & $\begin{array}{c}\text { Male } \\
\mathbf{n}\end{array}$ & $\begin{array}{c}\text { Male } \\
\mathbf{n} \% \mathbf{( S E})\end{array}$ & $\begin{array}{c}\text { Female } \\
\mathbf{n}\end{array}$ & $\begin{array}{c}\text { Female } \\
\mathbf{n} \% \text { (SE) }\end{array}$ \\
Total & & 450 & & 425 & \\
Age & $12-13$ & 122 & $27.4(2.73)$ & 136 & $28.5(2.68)$ \\
& $14-15$ & 167 & $38.5(2.92)$ & 133 & $34.7(3.11)$ \\
& $16-17$ & 161 & $34.1(2.88)$ & 156 & $36.8(3.08)$ \\
Race/Ethnicity & White & 136 & $57.2(2.44)$ & 125 & $60.4(2.33)$ \\
& Hispanic & 153 & $20.0(1.51)$ & 156 & $19.7(1.47)$ \\
& Black & 115 & $15.3(1.32)$ & 112 & $15.8(1.37)$ \\
& Other & 46 & $7.5(1.45)$ & 32 & $4.1(0.94)$ \\
BMI & Not Overweight & 102 & $23.4(2.34)$ & 105 & $25.2(2.23)$ \\
& Overweight & 348 & $76.6(2.34)$ & 320 & $74.8(2.23)$ \\
& Pctive & 120 & $29.0(2.82)$ & 63 & $18.7(2.65)$ \\
& PA & 330 & $71.0(2.82)$ & 362 & $81.3(2.65)$ \\
& Not Active & & & & \\
BMI/PA & NOA & 24 & $6.4(1.68)$ & 10 & $2.8(1.14)^{*}$ \\
Category & NONA & 78 & $17.0(2.25)$ & 95 & $22.3(2.30)$ \\
& OA & 96 & $22.7(2.47)$ & 53 & $15.9(2.45)$ \\
& ONA & 252 & $53.9(2.98)$ & 267 & $59.0(2.93)$
\end{tabular}

$\overline{\text { SE, standard error; White, Non-Hispanic White; Black, Non-Hispanic Black; Hispanic, Other Hispanic and }}$ Mexican American; Other, Non-Hispanic Other Race-Including Multi-Racial; BMI, body mass index; participants were considered "Overweight" if their BMI was at or above the 85th percentile (age- and sexspecific); PA, physical activity in minutes per day calculated as follows: (average minutes of moderate/ vigorous activity per day $\mathrm{x}$ average days of moderate/vigorous activity per week) / 7; participants were considered "Active" if their average minutes per day were at or above 60; NOA, not overweight, active; NONA, not overweight, not active; OA, overweight, active; ONA, overweight, not active.

*The following estimates should be interpreted with caution due to a relative standard error of $>30 \%$.

Table 2 illustrates the results of the regression analysis demonstrating the association between BMI/PA categorization and cMetS score, MAP z-score, FPG zscore, HDL-C z-score, and TG z-score. Note that HDL-C was inversed to match the directionality of the other variables; therefore, a higher HDL-C z-score is less desirable. The contribution of sex in the overall model was significant $(\mathrm{p}=0.0062)$. Overall, when compared to NOA adolescents, cMetS score in those classified as OA and ONA were significantly higher $(\mathrm{p}<0.05$ and $\mathrm{p}<0.01$, respectively). Only ONA adolescents 
demonstrated significantly higher FPG and HDL-C z-scores compared to those NOA $(p<0.01$ and $p<0.05$, respectively), whereas higher TG $\mathrm{z}$-score was observed for the OA and ONA groups $(\mathrm{p}<0.01$ and $\mathrm{p}<0.001$, respectively). Females demonstrated significantly lower cMetS score, FPG z-score and HDL-C z-score when compared to males. Increasing age was positively related to cMetS score and MAP z-score.

Table 2. Association between BMI/PA categorization and cMetS score (MAP, FG, HDL-C, TRI) in U.S. adolescents: 2007-2012 NHANES.

\begin{tabular}{|c|c|c|c|c|c|}
\hline & $\begin{array}{c}\text { cMetS } \\
\text { score }(\beta)\end{array}$ & $\begin{array}{c}\text { MAP } \\
(\boldsymbol{\beta})\end{array}$ & $\begin{array}{c}\text { FPG } \\
(\boldsymbol{\beta})\end{array}$ & $\begin{array}{c}\text { HDL-C } \\
\text { (B) }\end{array}$ & $\begin{array}{l}\text { TG } \\
(\beta)\end{array}$ \\
\hline \multicolumn{6}{|l|}{ BMI/PA } \\
\hline NOA & - & - & - & - & - \\
\hline NONA & 0.84 & 0.19 & 0.05 & 0.43 & 0.18 \\
\hline $\mathrm{OA}$ & $1.10 *$ & 0.16 & 0.16 & 0.37 & $0.42 * *$ \\
\hline ONA & $1.59 * *$ & 0.16 & $0.29 * *$ & $0.67 *$ & $0.47 * * *$ \\
\hline \multicolumn{6}{|l|}{ Sex } \\
\hline Males & - & - & - & - & - \\
\hline Females & $-0.53 * *$ & -0.11 & $-0.26 * * *$ & $-0.18 *$ & 0.02 \\
\hline \multicolumn{6}{|c|}{ Race/Ethnicity } \\
\hline White & - & - & - & - & - \\
\hline Hispanic & 0.03 & -0.14 & $0.15^{*}$ & -0.01 & 0.03 \\
\hline Black & $-1.09^{* *}$ & 0.07 & $-0.23 * *$ & $-0.41 * * *$ & $-0.52 * * *$ \\
\hline Other & $-0.65^{*}$ & -0.22 & -0.04 & -0.21 & -0.17 \\
\hline \multicolumn{6}{|l|}{ Age } \\
\hline $12-13$ & - & - & - & - & - \\
\hline $14-15$ & $0.52 *$ & $0.10 * *$ & 0.02 & 0.20 & 0.02 \\
\hline $16-17$ & $0.66 * *$ & $0.09 * * *$ & -0.14 & 0.20 & 0.11 \\
\hline
\end{tabular}

Data are standardized regression $\beta$-coefficients $(95 \% \mathrm{CI})$ and outcomes are expressed as standardized $\mathrm{z}$ scores. All outcomes are adjusted for sex, race/ethnicity, and age. cMetS score, Clustered metabolic syndrome risk score; MAP, mean arterial pressure; FPG, fasting plasma glucose; HDL-C, high-density lipoprotein cholesterol; TRI, triglycerides; BMI/PA, body mass index/physical activity; NOA, not overweight, active; NONA, not overweight, not active; OA, overweight, active; ONA, overweight, not active. ${ }^{*} \mathrm{P}<0.05 ;{ }^{* * \mathrm{P}}<0.01 ;{ }^{* * *} \mathrm{P}<0.001$.

Figure 1 illustrates sex-specific effects of BMI and PA on cMetS score. While only ONA males demonstrated significantly higher cMetS score when compared to the referent group of NOA males $(\mathrm{p}<0.01)$, OA and ONA females cMetS score were 
significantly higher when compared to NOA females $(\mathrm{p}<0.01$ and $\mathrm{p}<0.0001$, respectively).

Figure 1. Association between BMI/PA categorization and cMetS score in U.S. adolescents stratified by sex: NHANES 2007-2012.

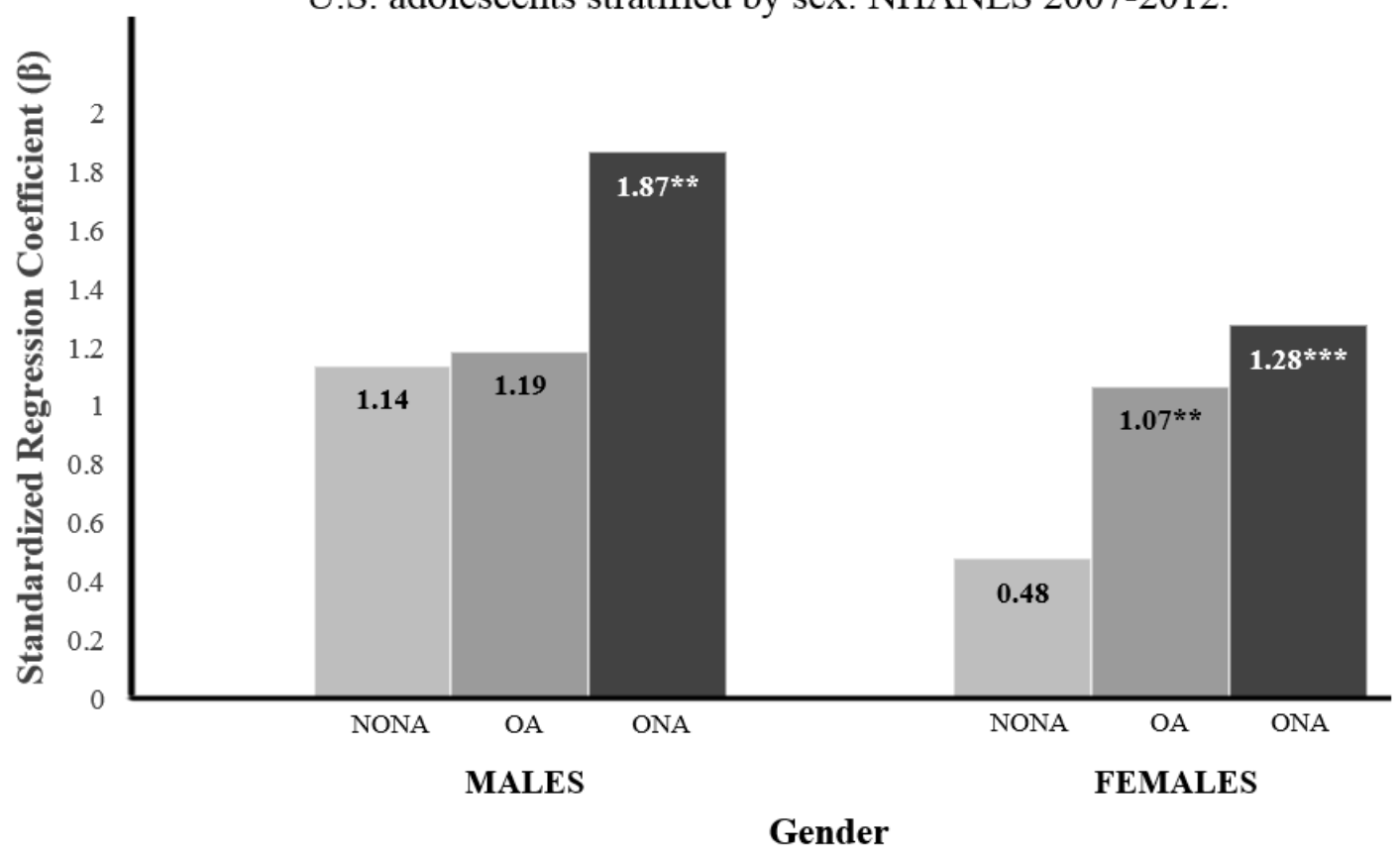

Data are standardized regression $\beta$-coefficients $(95 \% \mathrm{CI})$ and outcomes are expressed as standardized $\mathrm{z}$ scores. All outcomes are adjusted for sex, race/ethnicity, and age. cMetS score, Clustered metabolic syndrome risk score. Referent group is NOA. $* \mathrm{P}<0.05 ; * * \mathrm{P}<0.01 ; * * * \mathrm{P}<0.001$

Tables 3 and 4 demonstrate the associations between categorization based on BMI and PA, race/ethnicity, and age with individual components of the cMetS score in males and females, respectively. Interestingly, while NONA and ONA males demonstrated significantly higher HDL-C z-scores when compared to the referent, no significant differences were observed in females. Additionally, while a significant positive doseresponse relationship was observed between HDL-C z-score and age in males, the same was not observed in females. It was also observed that in ONA females only, FPG zscore was significantly higher when compared to the referent. In both males and females, it was observed that MAP was positively associated with increasing age, and that those 
OA and ONA both demonstrated significantly higher TG z-score when compared to the referent.

Table 3. Association between BMI/PA categorization and cMetS score components (MAP, FG, HDL-C, TRI) in U.S. adolescent males: NHANES 2007-2012.

\begin{tabular}{ccccc} 
& $\begin{array}{c}\text { MAP } \\
(\boldsymbol{\beta})\end{array}$ & $\begin{array}{c}\text { FPG } \\
(\boldsymbol{\beta})\end{array}$ & $\begin{array}{c}\text { HDL-C } \\
(\boldsymbol{\beta})\end{array}$ & $\begin{array}{c}\text { TG } \\
(\boldsymbol{\beta})\end{array}$ \\
\hline BMI/PA & & & & - \\
NOA & - & - & - & 0.10 \\
NONA & 0.23 & -0.06 & $0.87^{* *}$ & $0.43^{*}$ \\
OA & 0.21 & 0.14 & 0.41 & $0.65^{* *}$ \\
ONA & 0.12 & 0.20 & $0.91^{* *}$ &
\end{tabular}

\section{Race/Ethnicity}

White

Hispanic

$-0.12$

$0.18^{*}$

0.08

0.08

Black

0.12

$-0.18$

$-0.44 * *$

$-0.46^{* *}$

Other

$-0.17$

$-0.02$

$-0.09$

$-0.24$

\section{Age}
12-13
14-15
$0.30^{*}$
0.05
$0.44 * *$
0.10
16-17
$0.72 * * *$
$-0.03$
$0.55 * *$
0.18

Data are standardized regression $\beta$-coefficients $(95 \% \mathrm{CI})$ and outcomes are expressed as standardized $\mathrm{z}$ scores. All outcomes are adjusted for sex, race/ethnicity, and age. cMetS score, Clustered metabolic syndrome risk score; MAP, mean arterial pressure; FPG, fasting plasma glucose; HDL-C, high-density lipoprotein cholesterol; TRI, triglycerides; BMI/PA, body mass index/physical activity; NOA, not overweight, active; NONA, not overweight, not active; OA, overweight, active; ONA, overweight, not active. ${ }^{*} \mathrm{P}<0.05 ; * * \mathrm{P}<0.01 ; * * * \mathrm{P}<0.001$.

Table 4. Association between BMI/PA categorization and cMetS score components (MAP, FG, HDL-C, TRI) in U.S. adolescent females: NHANES 2007-2012.

\begin{tabular}{ccccc} 
& $\begin{array}{c}\text { MAP } \\
(\boldsymbol{\beta})\end{array}$ & $\begin{array}{c}\text { FPG } \\
(\boldsymbol{\beta})\end{array}$ & $\begin{array}{c}\text { HDL-C } \\
(\boldsymbol{\beta})\end{array}$ & $\begin{array}{c}\text { TG } \\
(\boldsymbol{\beta})\end{array}$ \\
$\mathbf{B M I} / \mathbf{P A}$ & & & - & - \\
NOA & - & - & -0.10 & 0.16 \\
NONA & 0.21 & 0.26 & 0.25 & $0.40^{* *}$ \\
OA & 0.18 & 0.29 & 0.30 & $0.25^{* * *}$ \\
ONA & 0.26 & $0.51^{* *}$ & & \\
& & & - & - \\
Race/Ethnicity & - & - & -0.11 & 0.01 \\
White & $-0.19^{*}$ & 0.08 & $-0.44^{* *}$ & $-0.56^{* * *}$ \\
Hispanic & -0.01 & $-0.29^{* *}$ & -0.34 & -0.06 \\
Black & -0.26 & -0.05 & & \\
Other & & & & \\
\hline
\end{tabular}




\section{Age}

12-13

14-15

16-17

0.27 *

$0.29 * *$

$-0.02$

$-0.24 * *$

$-0.02$

$-0.14$

$-0.04$

0.05

Data are standardized regression $\beta$-coefficients $(95 \% \mathrm{CI})$ and outcomes are expressed as standardized $\mathrm{z}$ scores. All outcomes are adjusted for sex, race/ethnicity, and age. cMetS score, Clustered metabolic syndrome risk score; MAP, mean arterial pressure; FPG, fasting plasma glucose; HDL-C, high-density lipoprotein cholesterol; TRI, triglycerides; BMI/PA, body mass index/physical activity; NOA, not overweight, active; NONA, not overweight, not active; OA, overweight, active; ONA, overweight, not active. ${ }^{*} \mathrm{P}<0.05 ; * * \mathrm{P}<0.01 ; * * * \mathrm{P}<0.001$.

\section{Discussion}

In a large nationally representative sample of U.S. adolescents, it was observed that those who were OA and ONA demonstrated significantly higher cMetS score when compared to those who were NOA. These results support previous literature suggesting that adiposity may mediate the existing relationship between PA and cMetS score in youth (18-19). It should be noted that BMI is essentially a proxy for obesity, a chronic condition heavily associated with a number of unhealthy dietary and lifestyle habits. These contributors will affect the degree of one's obesity-related health risk.

A study by Vaisto et al. (18) reported the independent and combined associations of PA and sedentary behavior with cardiometabolic risk in children. Their sample $(\mathrm{n}=$ 468) consisted of six to eight-year-old Finnish children who participated in the Physical Activity and Nutrition in Children (PANIC) Study between 2007 and 2009. Volumes and type of both habitual PA and sedentary behavior (SB) were assessed by the PANIC Physical Activity Questionnaire. These reports were further validated using the Actiheart monitor, which utilizes a combination of heart rate and accelerometer measurements; total PA measured by the questionnaire correlated positively with the total PA measured by the Actiheart monitor $(\mathrm{r}=0.37, \mathrm{p}=0.033)$. A continuous cMetS score was derived from the standardizing and summing the following risk factors: WC, insulin, FG, TG, HDL-C, 
and the mean of systolic and diastolic BP. While it was found that total PA volume was significantly associated with cardiometabolic risk $(\beta=-0.135, \mathrm{p}<0.01)$, these relationships were no longer significant $(\beta=-0.048, p=0.232)$ following adjustments for body fat percentage (DXA). These findings, along with the present study, demonstrate the potentially mediating effect of adiposity on the metabolic benefits of PA.

The findings of Heshmat et al. (19) also suggest that adiposity mediates the relationship between PA and cMetS score. A cross-sectional analysis was performed in a sample of 5,625 Iranian students between the ages of 10-18 in order to examine the potential associations of PA on interactions between excess body weight and cMetS score. The sample included participants from the third survey of the Childhood and Adolescence Surveillance and Prevention of Adult Non-Communicable Disease (CASPIAN) study conducted in 2009-2010. Leisure time PA was assessed using a validated questionnaire and participants were categorized according to how many days per week they participated in PA outside of school. The cMetS score included components such as WC, mean arterial pressure (MAP), HDL-C, TG, and FG. It was reported that although a relationship existed between leisure-time PA (LTPA) and clustered MetS components $(\beta=1.13, \mathrm{p}<0.05)$, adjustment for BMI and screen time resulted in the loss of statistical significance $(\beta=1.10, \mathrm{p}>0.05)$. It was also shown that BMI percentiles were associated with cMetS, independent of LTPA and screen time $(\beta=1.07, \mathrm{p}<0.05)$

The present study also observed that only ONA adolescents demonstrated significantly higher FPG and HDL-C z-scores compared to those NOA $(p<0.01$ and $\mathrm{p}<0.05$, respectively). Previous research has observed that activity may be protective of 
obesity-related components of metabolic risk. In 2006, Ekelund et al. (14) demonstrated that the relationship between PA and FPG in European adolescents $(n=1921)$ remained significant $(\mathrm{p}<0.001)$ following adjustment for the sum of four skin folds. A similar significant relationship was reported in a previously discussed follow-up analysis by Ekelund et al. (15) wherein FPG was inversely associated with moderate, vigorous, and TPAV in European children and adolescents $(\beta=-0.11, \mathrm{p}<0.001 ; \beta=-0.10, \mathrm{p}<0.001$; and $\beta=-0.11, \mathrm{p}<0.001$ in moderate, vigorous and TPAV, respectively). However, both of these studies observed that after adjusting for adiposity, the relationship between PA and HDL-C was no longer significant.

It was also observed in the present analysis that higher TG z-scores were observed for the OA and ONA groups ( $p<0.01$ and $p<0.001$, respectively) when compared to the referent. In a cross-sectional analysis of 5,625 Iranian students between the ages of 10-18, Heshmat et al. (19) observed that there was no significant association found between LTPA and TG concentration ( $\mathrm{p}=0.08)$. Additionally, TG were significantly positively associated with BMI percentile, independent of LTPA $(p<0.001)$. These findings collectively suggest that regardless of activity level, adiposity is a predictor for undesirable levels of TG.

The present study observed that while only ONA males demonstrated significantly higher cMetS score when compared to their respective male referent group, both OA and ONA female's cMetS scores were significantly higher when compared to the referent. This suggests that in male adolescents, the mechanisms by which cMetS score is significantly increased may be different than those in similarly aged females. Physical activity seems to be protective of an increased cMetS score in overweight male 
adolescents. In contrast, females demonstrated increased cMetS score when classified as overweight regardless of PA levels. Additionally, while males demonstrated significantly higher HDL-C z-scores when categorized as "Not Active", regardless of BMI, no significant differences in HDL-C were observed among females. Therefore, in males only, activity is predictive of HDL-C, regardless of weight status. A significant positive dose-response relationship was also observed between HDL-C z-score and age in males only.

Previous literature has demonstrated that in adolescents, different associations are seen between PA and HDL-C in boys and girls. Pahkala et al. (16) studied a sample of 13-year old adolescents $(n=542)$ recruited from an ongoing atherosclerosis prevention study in Finland. Leisure-time activity was assessed using a self-administered questionnaire, which included questions regarding the frequency, duration and intensity of the participant's LTPA. From these values, a PA index of MET hours per week (MET $\mathrm{h} / \mathrm{wk}$ ) was determined, and used to compare adolescents who performed $<5 \mathrm{MET} \mathrm{h} / \mathrm{wk}$ of PA to those who performed $\geq 5 \mathrm{MET} \mathrm{h} / \mathrm{wk}$. The risk factors included in their cMetS score included BMI, HDL-C, TG and systolic and diastolic BP. It was reported that in girls, LTPA was inversely associated with HDL-C only prior to adjusting for adiposity $(\beta=0.045, \mathrm{p}<0.05)$. When BMI was included in the analysis, this association did not remain significant. In contrast, LTPA had a significant beneficial effect on HDL-C following adjustment for BMI in boys $(\beta=0.043, p<0.05)$. These results suggest that in girls only, adiposity may have a mediating effect on the significant relationship between LTPA and HDL-C, though this is not suggested by the results of the present study. However, these findings in combination with those in the present study do suggest that 
the mechanisms by which HDL-C is affected by PA and adiposity may be different in adolescents depending on sex. Further research should aim to study the effects of PA and BMI on individual metabolic risk factors in adolescents stratified by sex.

The present study is not without limitations. First, due to the cross-sectional nature of the study, causality cannot be inferred. Second, due to the fact that activity levels were measured via self-report, volumes and intensities of PA are subject to recall and report bias. In addition, the cMetS score should be interpreted with caution due to the fact that the findings will only apply to a cMetS score comprised of the same metabolic components (MAP, FPG, HDL-C, and TG). Finally, all self-report data may be susceptible to the social desirability effect. The study design, however, also presents many strengths. The sample utilized is nationally representative, therefore offers strong external validity. The size of the sample provides increased statistical power. Bias is somewhat limited due to the fact that objective means of measurement are primarily used for the outcome variables. Finally, the cMetS score as a continuously distributed outcome measure serves to further maximize statistical strength.

In conclusion, the cMetS scores were higher in OA and ONA adolescents when compared to those classified as NOA. While only ONA males demonstrated significantly higher cMetS score when compared to their respective male referent group, both OA and ONA cMetS scores were significantly higher in females. To our knowledge, this is the first study to examine cMetS score among adolescents categorized by PA and BMI in a nationally representative sample of U.S. adolescents. To our knowledge, the combined impact of PA and BMI on the cMetS score has yet to be examined in an analysis using a nationally representative sample of U.S. adolescents. The present study will add to 
existing literature by potentially identifying an important public health focus (PA, adiposity or both), and also by identifying whether any sex-differences exist. 


\section{References}

1. Anderson L, Harro M, Sardinha L, Froberg K, Ekelund U, Brage S, et al. Physical activity and clustered cardiovascular risk in children: A cross-sectional study (the European Youth Heart Study). Lancet. 2006(368):299-304.

2. Boreham C, Riddoch C. The physical activity, fitness and health of children. JSports Sci. 2001(19):915-29.

3. Carson V, Ridgers ND, Howard BJ, Winkler EA, Healy GN, Owen N, et al. Lightintensity physical activity and cardiometabolic biomarkers in US adolescents. PLoS One. 2013;8(8):e71417.

4. Steinberger J, Daniels SR, American Heart Association Atherosclerosis Hp, and Obesity in the Young Committee (Council on Cardiovascular Disease in the Young), American Heart Association Diabetes Committee (Council on Nutrition PyA, and Metabolism). Obesity, insulin resistance, diabetes, and cardiovascular risk in children: an American Heart Association scientific statement from the Atherosclerosis, Hypertension, and Obesity in the Young Committee (Council on Cardiovascular Disease in the Young) and the Diabetes Committee (Council on Nutrition, Physical Activity, and Metabolism). Circulation. 2003;107(10):1448-53.

5. Ekelund U, Brage S, Froberg K, Harro M, Anderssen SA, Sardinha LB, et al. TV viewing and physical activity are independently associated with metabolic risk in children: the European Youth Heart Study. PLoS Med. 2006;3(12):e488.

6. Sinha R, Fisch G, Teague B, Tamborlane WV, Banyas B, Allen K, et al. Prevalence of impaired glucose tolerance among children and adolescents with marked obesity. $N$ Engl J Med. 2002;346(11):802-10. 
7. Whitaker RC, Wright JA, Pepe MS, Seidel KD, Dietz WH. Predicting obesity in young adulthood from childhood and parental obesity. $N$ Engl J Med. 1997;337(13):869-73.

8. Eisenmann JC, Wickel EE, Welk GJ, Blair SN. Relationship between adolescent fitness and fatness and cardiovascular disease risk factors in adulthood: the Aerobics Center Longitudinal Study (ACLS). Am Heart J. 2005;149(1):46-53.

9. van Dam RM, Willett WC, Manson JE, Hu FB. The relationship between overweight in adolescence and premature death in women. Ann Intern Med. 2006;145(2):91-7.

10. Grundy SM, Cleeman JI, Daniels SR, et al. Diagnosis and management of the metabolic syndrome: an American Heart Association/National Heart, Lung, and Blood Institute scientific statement: executive summary. Circulation. 2005;112(17):2735-52. 11. Cook S, Auinger P, Li C, Ford ES. Metabolic syndrome rates in United States adolescents, from the National Health and Nutrition Examination Survey, 1999-2002. $J$ Pediatr. 2008;152(2):165-70.

12. Miller JM, Kaylor MB, Johannsson M, Bay C, Churilla JR. Prevalence of metabolic syndrome and individual criterion in US adolescents: 2001-2010 National Health and Nutrition Examination Survey. Metab Syndr Relat Disord. 2014;12(10):527-32 .

13. Bailey DP, Boddy LM, Savory LA, Denton SJ, Kerr CJ. Associations between cardiorespiratory fitness, physical activity and clustered cardiometabolic risk in children and adolescents: the HAPPY study. Eur J Pediatr. 2012;171(9):1317-23.

14. Ekelund U, Brage S, Froberg K, Harro M, Anderssen SA, Sardinha LB, et al. TV viewing and physical activity are independently associated with metabolic risk in children: the European Youth Heart Study. PLoS Med. 2006;3(12):e488.10. 
15. Ekelund U, Anderssen SA, Froberg K, Sardinha LB, Andersen LB, Brage S, et al. Independent associations of physical activity and cardiorespiratory fitness with metabolic risk factors in children: the European youth heart study. Diabetologia. 2007;50(9):183240.

16. Pahkala K, Heinonen OJ, Lagström H, Hakala P, Hakanen M, Hernelahti M, et al. Clustered metabolic risk and leisure-time physical activity in adolescents: effect of dose? Br J Sports Med. 2012;46(2):131-7.

17. Chaput JP, Lambert M, Mathieu ME, Tremblay MS, O' Loughlin J, Tremblay A. Physical activity vs. sedentary time: independent associations with adiposity in children. Pediatr Obes. 2012;7(3):251-8.

18. Väistö J, Eloranta AM, Viitasalo A, Tompuri T, Lintu N, Karjalainen P, et al. Physical activity and sedentary behaviour in relation to cardiometabolic risk in children: cross-sectional findings from the Physical Activity and Nutrition in Children (PANIC) Study. Int J Behav Nutr Phys Act. 2014;11:55.

19. Heshmat R, Shafiee G, Kelishadi R, Babaki AE, Motlagh ME, Arefirad T, et al. Is the association of continuous metabolic syndrome risk score with body mass index independent of physical activity? The CASPIAN-III study. Nutr Res Pract. 2015;9(4):404-10.

20. Bai Y, Chen S, Laurson KR, Kim Y, Saint-Maurice PF, Welk GJ. The Associations of Youth Physical Activity and Screen Time with Fatness and Fitness: The 2012 NHANES National Youth Fitness Survey. PLoS One. 2016;11(1):e0148038. 21. United States Department of Health and Human Services. The National Health and Nutrition Examination Survey. 2016. 
22. Centers for Disease Control and Prevention (CDC). National Center for Health Statistics (NCHS). National Health and Nutrition Examination Survey Analytic and Reporting Guidelines. U.S. Department of Health and Human Services, Center for Disease Control and Prevention, ed. 2006. https://www.cdc.gov/nchs/data/nhanes/nhanes_03_04/nhanes_analytic_guidelines_ dec_2005.pdf [Accessed 26 February 2017].

23. Carson V, Staiano AE, Katzmarzyk PT. Physical activity, screen time, and sitting among U.S. adolescents. Pediatr Exerc Sci. 2015;27(1):151-9.

24. 2008 Physical Activity Guidelines for Americans: Be Active, Healthy, And Happy! U.S. Department of Health and Human Services; 2008. p. 7-20.

25. National Health and Nutrition Examination Survey 2011-2012. Laboratory Procedure Manuals. NCHS (National Center for Health Statistics). Atlanta, GA: Centers for Disease Control and Prevention, National Center for Health Statistics. 2013. https://www.cdc.gov/ nchs/nhanes/nhanes2011-2012/lab_methods_11_12.htm [Accessed 26 February 2017]. 26. SAS. Base 9.4 Procedures Guide. 2013.

27. Centers for Disease Control and Prevention (CDC). National Center for Health Statistics (NCHS). National Health and Nutrition Examination Survey Analytic and Reporting Guidelines. U.S. Department of Health and Human Services, Center for Disease Control and Prevention, ed. 2006. https://www.cdc.gov/nchs/data/nhanes/nhanes_03_04/nhanes_analytic_guidelines_ dec_2005.pdf [Accessed 26 February 2017]. 
Appendices 


\section{Appendix A}

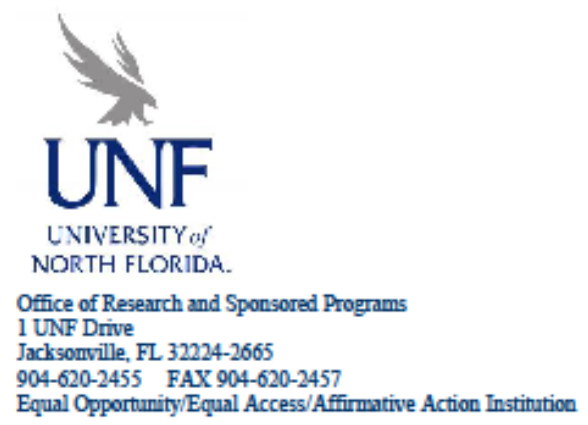

MEMORANDUM

DATE: $\quad$ October 25,2016

TO: $\quad$ Ms. Bethany Williams

VIA: Dr. James Churilla

Clinical and Applied Movement Sciences

FROM: Dr. Jennifer Wesely, Chairperson

On behalf of the UNF Institutional Review Board

RE: "Physical activity, body mass index and cardio-metabolic risk in U.S. adolescents"

This is to advise you the Human Subject Research Determination Form for the project named above was reviewed on behalf of the UNF Institutional Review Board, and has subsequently been granted this waiver of IRB review. As such, this project was declared "not research involving human subjects" based on the federal definition as stated in the U.S. Department of Health and Human Services Code of Federal Regulations 45 CFR 46.102. Therefore, it is not necessary for this project to be reviewed and approved by the UNF IRB. However, be aware that the principal investigator is not absolved from complying with other federal, state, or local laws or institutional policies and procedures.

Thank you for submitting your work for IRB review. We appreciate that you understand the value of $I R B$ review of human subject research and projects conducted at UNF. Any unanticipated problems involving risk and any occurrence of serious harm to subjects and others shall be reported promptly to the IRB. This waiver should be kept for your records and applies to your project in the form and content as submitted to the IRB for review. Any variations or modifications to this waived project as related to dealing with human subjects must be cleared with the $\mathbb{R} B$ prior to implementing such changes.

Should you have questions regarding your project or any other IRB items, please contact the research integrity unit of the Office of Research and Sponsored Programs by emailing $\underline{\mathbb{R} B @ a u n f . e d u}$ or calling (904) 620-2455.

This letter has been electronically signed in accordance with all applicable regulations, and a copy is retained within UNF's records. 


\section{Vita}

Bethany Dawn Williams is a graduate research assistant and instructor in the Clinical and Applied Movement Sciences department at the University of North Florida in Jacksonville, FL. She also obtained her Bachelor of Science in Health Degree concentrating in Exercise Science from the University of North Florida in 2015. She began her graduate career in Physical Activity Epidemiology within the Master of Science in Health program concentrating in Exercise Science and Chronic Disease under the mentorship of Dr. James Churilla in the Fall of 2015.

Her research studies have included the investigation of the associations between physical activity, adiposity, resting heart rate and metabolic risk factors in large, nationally representative data sets. Her primary interests have included investigating the combined associations of activity and body mass index on metabolic risk factors in U.S. adolescents. 